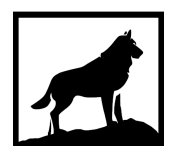

Michigan

Technological

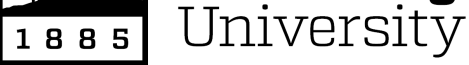

Michigan Technological University

Digital Commons @ Michigan Tech

GAS AND HEAT FLUXES DURING MULTIPLE EFFUSIVE ERUPTIONS OF PITON DE LA FOURNAISE (RÉUNION) AND THEIR IMPLICATIONS FOR MAGMATIC PROCESSES

Pauline Verdurme

Michigan Technological University, pverdurm@mtu.edu

Copyright 2021 Pauline Verdurme

Recommended Citation

Verdurme, Pauline, "GAS AND HEAT FLUXES DURING MULTIPLE EFFUSIVE ERUPTIONS OF PITON DE LA FOURNAISE (RÉUNION) AND THEIR IMPLICATIONS FOR MAGMATIC PROCESSES", Open Access Master's Thesis, Michigan Technological University, 2021.

https://doi.org/10.37099/mtu.dc.etdr/1279

Follow this and additional works at: https://digitalcommons.mtu.edu/etdr

Part of the Volcanology Commons 


\title{
GAS AND HEAT FLUXES DURING MULTIPLE EFFUSIVE ERUPTIONS OF PITON DE LA FOURNAISE (RÉUNION) AND THEIR IMPLICATIONS FOR MAGMATIC PROCESSES
}

\author{
By \\ Pauline Verdurme \\ A THESIS \\ Submitted in partial fulfillment of the requirements for the degree of \\ MASTER OF SCIENCE \\ In Geology \\ MICHIGAN TECHNOLOGICAL UNIVERSITY \\ 2021
}

(C) 2021 Pauline Verdurme 
This thesis has been approved in partial fulfillment of the requirements for the Degree of MASTER OF SCIENCE in Geology.

Department of Geological and Mining Engineering and Sciences

Thesis Advisor: Simon Carn

Committee Member: $\quad X i n X i$

Committee Member: Andrew Harris

Department Chair: Aleksey Smirnov 


\section{Table of contents}

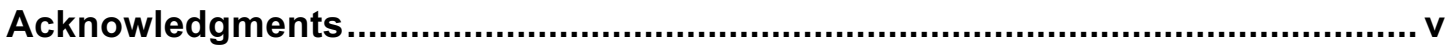

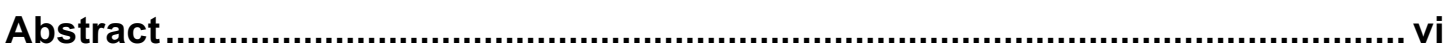

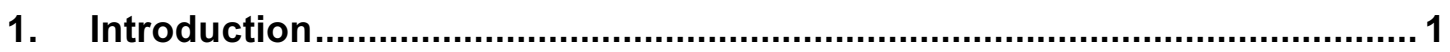

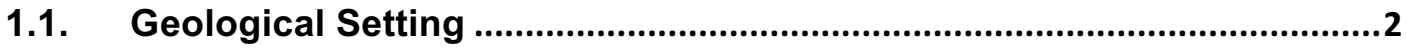

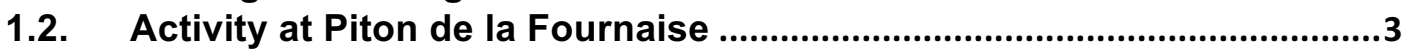

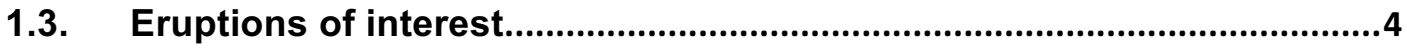

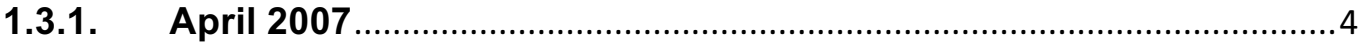

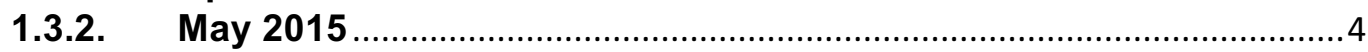

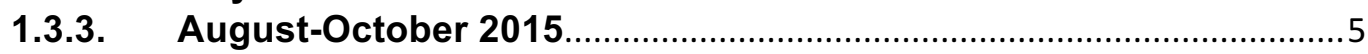

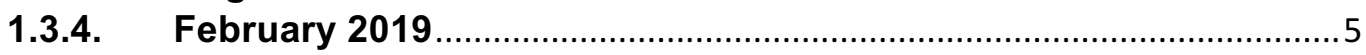

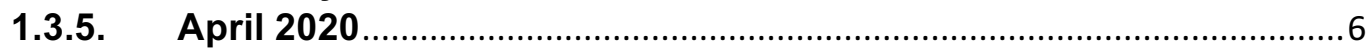

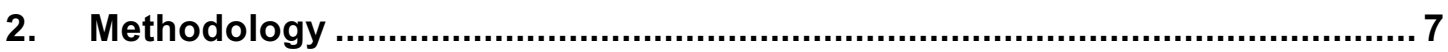

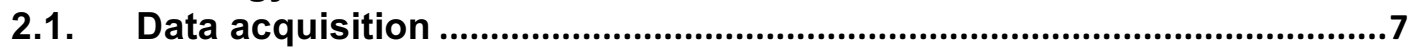

2.1.1. Tropospheric $\mathrm{SO}_{2}$ concentration measured from space ................

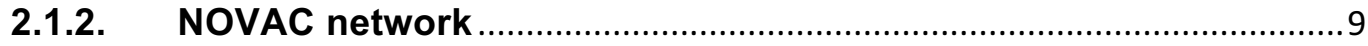

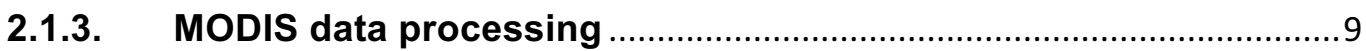

2.2. Estimation of lava discharge rate from MODIS data ............................. 11

2.3. Conversion of $\mathrm{SO}_{2}$ to lava masses....................................................12

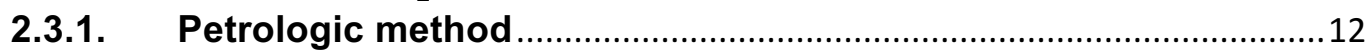

2.3.2. Petrologic method including a time parameter ..............................13

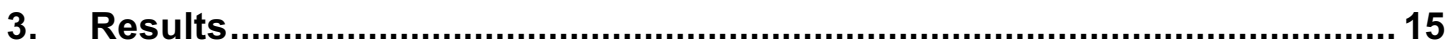

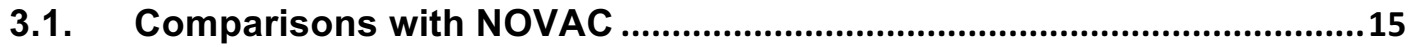

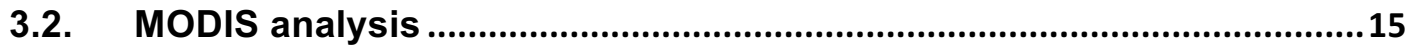

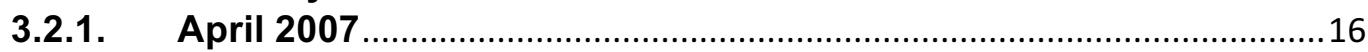

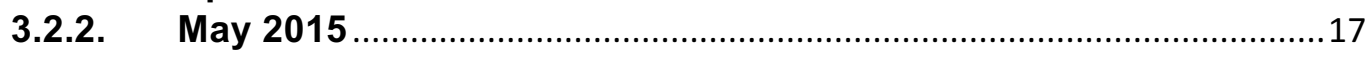

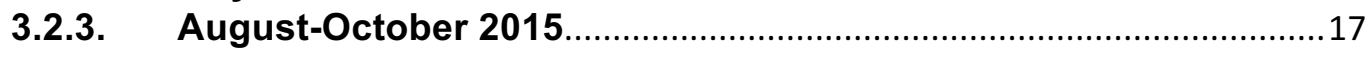

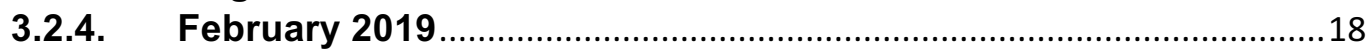

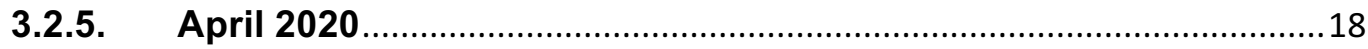

3.2.6. Thermally-derived TADR data: Sum up ........................................19

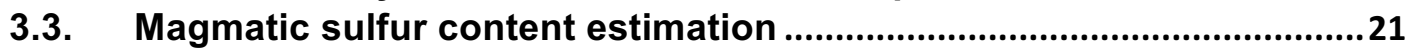

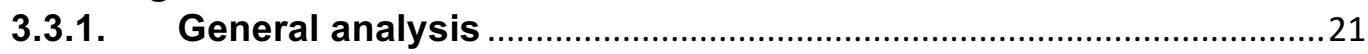

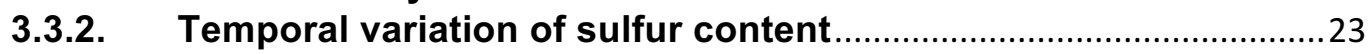

3.4. Daily lava volume estimation from sulfur content................................24

3.4.1. Fixed sulfur content within the melt inclusions ............................25

3.4.2. Variable sulfur content within melt inclusions ................................25

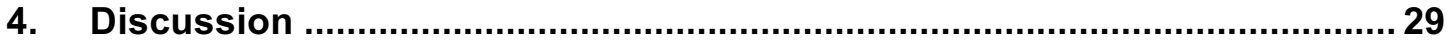

4.1. $\mathrm{SO}_{2}$ flux measurements from space and the NOVAC network .............29

4.2. Discharge of the magmatic system .....................................................29

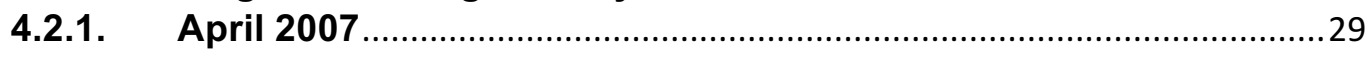

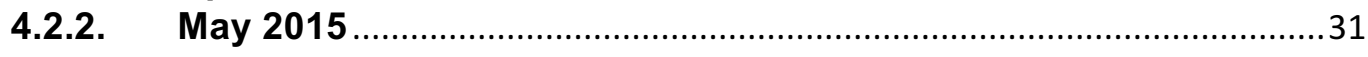

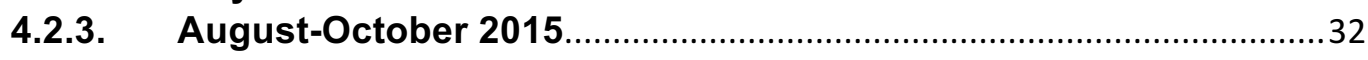

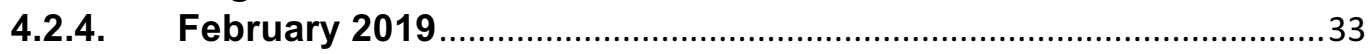




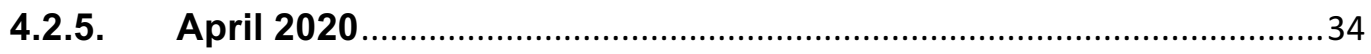

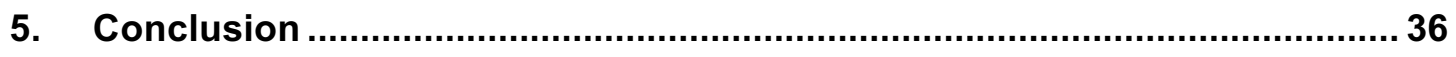

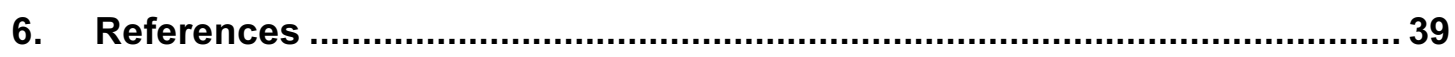

\section{Appendix}

Appendix 1: $\mathrm{SO}_{2}$ time-series at Piton de la Fournaise during the eruptions of interest............................................................................................................ 45 Appendix 2: Effusion rates and cumulative volumes of erupted lava.................................................................................................................... 46

Appendix 3: Bow tie effect on the MODIS

image....................................................................................................... 47 


\section{Acknowledgments}

Throughout the writing of this study I have received a great deal of support and assistance.

I would first like to thank the members of my dissertation committee for their time and patience to read my report.

Then, I would like to thank my supervisors, Simon Carn and Andrew Harris. Their continuous support during this study and their enthusiasm pushed me to sharpen my thinking and brought my work to a higher level. Also, thank you to Andrea Di Muro, Diego Coppola and Santiago Arellano for taking time to share with me their knowledge on multiple useful aspects for this study. I really enjoyed our discussions all over the project.

I would like to acknowledge the faculty and staff directory of the "Laboratoire Magmas et Volcans" as well as the University Clermont Auvergne that provided all the tools needed to complete my project and for giving the opportunity to work within the laboratory despite the sanitary conditions.

Furthermore, I could not have completed this dissertation without the support of my friends. Many thanks for the time spending together. Also, I do not forget my American guys: Kate, Gabriel, Nel and lullia (I cannot list all the names here, but you are always in my mind), who provided stimulating discussions as well as happy distractions to rest my mind outside of my research last year. To them I say: "I cannot wait to see you again and admire the sunset over the Lake Superior one more time on yours side."

Last but not the least, I would like to make a special dedicate to my parents and my brother for their love and support since I was born. They always encouraged me to be curious about how things work. You are always there for me and give me the strength to reach my dreams.

This master project is only the beginning of my extraordinary journey. 


\section{Abstract}

This study investigates five eruptions with different temporal trends of erupted mass and sulfur dioxide ( $\left.\mathrm{SO}_{2}\right)$ at Piton de la Fournaise (La Réunion). We acquired the daily $\mathrm{SO}_{2}$ emissions from three ultraviolet (UV) satellite instruments (the Ozone Monitoring Instrument [OMI], the Ozone Mapping and Profiler Suite [OMPS] and the Tropospheric Monitoring Instrument [TROPOMI]). The Time-Averaged-LavaDischarge Rate (TADR) has been obtained from two automatic systems: MIROVA and MODVOLC. Assuming that the lava volumes measured in the field are the most accurate, MIROVA gives the best estimation among all the methods investigated. It has also been demonstrated that a petrological approach might be a viable alternative, especially during cloudy weather that compromises the hot spot detection. Finally, in several eruptions we observe a terminal increase in TADR and $\mathrm{SO}_{2}$ emissions. We suggest that a deeper input may be at the origin of this eruptive process causing a pressurization of the magmatic system. 


\section{Introduction}

Volcanic eruptions are commonly preceded by a multitude of precursors including seismicity (e.g., seismic swarms and volcanic tremor), ground deformation and changes in gas composition or flux. All these warnings can be detected and tracked continuously by permanent ground stations and satellite observations (e.g., Peltier et al., 2009). Over years, development of technology for near-real time and continuous data collection has led to improvements in volcano monitoring and the anticipation of their eruptive behavior. We may distinguish the ultraviolet (UV) satellite instruments including the Ozone Monitoring Instrument (OMI), the Ozone Mapping and Profiler Suite (OMPS) and the Tropospheric Monitoring Instrument (TROPOMI), that allow daily monitoring of sulfur dioxide $\left(\mathrm{SO}_{2}\right)$ emissions. Thermal infrared (TIR) satellite sensors permit the detection of volcanic hotspots associated with surface activity (e.g., lava flows, lava lakes). Within this category, the Moderate Resolution Imaging Spectroradiometer (MODIS) Level 1B data, provided by NASA's Terra and Aqua sensors, are used as the basis for two automated volcano monitoring systems namely: MIROVA and MODVOLC. For further details on both algorithms, the reader can refer to Coppola et al. (2016) and Wright (2016).

Piton de la Fournaise (La Réunion, France) is one of the most active volcanoes in the world, producing frequent effusive basaltic eruptions of varying duration (averaging one eruption every nine months since 1985 (Roult et al., 2012)). The eruptions are accompanied by strong thermal infrared (TIR) signals and significant sulfur dioxide $\left(\mathrm{SO}_{2}\right)$ emissions detected by satellite instruments (Bhugwant et al., 2009; Coppola et al., 2017; Gouhier and Coppola, 2011). Despite this intense eruptive activity, it is important to note that during intra-eruptive phases the amount of emitted gas is very weak (Di Muro et al., 2016). The high frequency of eruptions in the recent years has provided an extensive dataset, which allows us to explore the relationships between eruptive heat and gas fluxes. It has been demonstrated that the plumbing system at Piton de la Fournaise is composed of several storage levels connected to each other by sills and dykes ranging from 0.5 
to about $15 \mathrm{~km}$ depth (Di Muro et al., 2014; Peltier et al., 2009). The majority of the eruptions occurring at Piton de la Fournaise appear to be fed by the shallowest reservoirs located between 0.5 to $1.5 \mathrm{~km}$ beneath the summit crater, with the main reservoir located at about 1.5-2.5 km depth (Peltier et al., 2010).

In this study, we estimate lava discharge rates by adapting the methodology of Harris et al., (2007) to five eruptions characterized by different trends at Piton de la Fournaise (April 2007, May 2015, August-October 2015, February 2019 and April 2020). The time-averaged-lava-discharge rates (TADR) are used to interpret the evolution of the effusive activity which in turn is compared with the $\mathrm{SO}_{2}$ emissions detected by three UV sensors and the temporal variation of the preeruptive sulfur (S) content within melt inclusions. The insights gained from this comparison allow us to explain the eruptive dynamics and degassing regime.

\subsection{Geological Setting}

Piton de la Fournaise is one of the most active volcanoes in the world, situated in the southeast part of La Réunion Island in the Southwest Indian Ocean (latitude: $21.244^{\circ} \mathrm{S}$, longitude: $55.708^{\circ} \mathrm{E}$ ) (Figure 1a). Geologically located in the Mascarene Basin, the volcanic activity is attributed to the hot spot activity which is at the origin of the Deccan Traps in India 65 Ma ago (Duncan 1981; Mahoney et al., 2002; Morgan 1983). This island is composed of three volcanic edifices: Les Alizés, Piton des Neiges (PdN), and Piton de la Fournaise (PdF). Les Alizés is completely eroded and has only been recognized by gravity, magnetic and drill hole investigations (Gailler et al., 2009; Gailler and Lénat 2010; Rançon, et al., 1989). It forms the south-eastern submarine flank of the edifice and could be about the same age as PdN ( 2 Myr) on the western side of the island. Piton des Neiges is the largest volcano on La Réunion, reaching an altitude of $3069 \mathrm{~m}$ above sea level (a.s.l) and erupted for the last time 12000 years ago (Deniel et al., 1992). Later, Piton de la Fournaise, formed on the southeast flank of PdN 500 ka ago, is still active and reaches $2362 \mathrm{~m}$ a.s.l. The formation of three calderas marks the evolution of PdF. The first formed about $15 \mathrm{ka}$ and is limited by the Rivière des 
Remparts to the south. The second caldera formed about $65 \mathrm{ka}$ and contains the Plaine des Sables and the upper Rivière de l'Est (Gillot and Nativel, 1989; Staudacher and Allègre, 1993). Finally, the Enclos Fouqué (Chevallier and Bachelery, 1981), a horseshoe-shaped depression opening eastward to the Indian Ocean, is the third and most recent caldera. Formed about 4500 years ago, most of the recent activity has occurred inside it (Bachelery, 1981). However, eruptions can occur outside the caldera, threatening the surrounding communities. The summit of Piton de la Fournaise is currently composed of two craters: Bory and Dolomieu (Figure 1c).

\subsection{Activity at Piton de la Fournaise}

Frequent basaltic effusive eruptions characterize this highly active shield volcano. In general, the events begin with the opening of a single or several fissures to feed lava fountains and lava flows. Scoria cones are progressively formed by the erupted products within the active area. Although dominated by effusive activity, a few explosive events have been recorded at Piton de la Fournaise (Michon et al., 2013), and collapse of the summit crater can also occur, such as in 2007 (Michon et al., 2007).

The eruptions typically last a few hours up to a few months with lava effusion rates typically ranging from one to a few tens of $\mathrm{m}^{3} \mathrm{~s}^{-1}$ (Coppola et al., 2017; Peltier et al., 2009). However, during the first days of an eruption, effusion rates can reach many $10 \mathrm{~s}$ to $100 \mathrm{~s}$ of $\mathrm{m}^{3} \mathrm{~s}^{-1}$. It is also important to note that, despite the intense eruptive activity, during intra-eruptive phases the amount of emitted gas is very low (Di Muro et al., 2016). There may be no degassing at all from the volcano between eruptive phases or the amount can be too low to be measured by satellite-based instruments, i.e., $\mathrm{SO}_{2}$ amounts may be below the detection threshold. This seems to be confirmed by measurements on the ground, which do not detect any emissions (Di Muro et al., 2016).

Also, following the April 2007 eruption characterized by the summit caldera collapse, the frequency of activity decreased with a repose period between 
February 2011 and June 2014. June 2014 is marked by increased seismicity and ground deformation consistent with charging of the shallow reservoir, and a resumption of surface activity (Coppola et al., 2017; Peltier et al., 2016). In 2015 there was intense activity with four eruptions in that year. The last eruption of 2015 (August 24 to October 31 ) ended with uncommon pulsatory activity probably related to a rapid magmatic refill (Coppola et al., 2017). Since 2016, a progressive increase in activity has been registered (Peltier et al., 2018).

\subsection{Eruptions of interest}

Five eruptions have been selected for this study: April 2007, May 2015, August-October 2015, February 2019 and April 2020. These eruptions are characterized by four different trends, those of: (1) paroxysmal eruption, (2) classic exponential decaying, (3) terminal burst, and (4) one with faulty data due to cloud cover (i.e., April 2020). See Figure 1c for the location of the different events.

\subsubsection{April 2007}

This paroxysmal eruption started on April 2 along a fissure East-Southeast from the summit and within the Grand Brûlé area. The surface activity was very intense, with lava fountains reaching a height of over $100 \mathrm{~m}$ accompanied by lava flows (Staudacher et al., 2009). On April 6, the Dolomieu crater collapsed, leading to higher lava fountains (more than $200 \mathrm{~m}$ ) and a high lava effusion rate $\left(200 \mathrm{~m}^{3}\right.$ $\left.\mathrm{s}^{-1}\right)$. As the eruption was very intense, UV and TIR instruments were saturated, meaning that only minimum bounds could be placed on discharge rates (Harris et al., 1997). Moreover, some lava flows entered the ocean and, consequently, the satellite-derived TADR estimation was increased by 30\% (Coppola et al., 2009). This paroxysmal eruption stopped on May 1, 2007.

\subsubsection{May 2015}

In mid-April 2015, deep seismicity as well as an increase in $\mathrm{CO}_{2}$ discharge were recorded, suggesting the rise of new, mafic magma from depth into the 
shallow reservoir at $0.5-1.5 \mathrm{~km}$ below sea level (Peltier et al., 2016). The eruption started on May 17 and stopped on May 30, being confined within the Enclos Fouqué caldera to the south-southeast close to the Château-Fort crater. This event was characterized by a high effusion rate at the beginning of the eruption followed by a classic exponential decrease as associated with supply from an increasingly depressurized source (Wadge, 1981). The erupted products reached a volume of $4.6 \pm 0.6 \mathrm{Mm}^{3}$. The May 2015 eruption emitted a more evolved magma than usual, ascribed to magma differentiation in the shallow reservoir (Sundermeyer et al., 2019).

\subsubsection{August-October 2015}

The August-October 2015 event, located on the south-west flank of the Dolomieu crater (east of the Rivals crater), can be divided into three phases. The first one occurred between August 24 and September 10 and was characterized by intense activity (initial TARD peak reaching $60 \mathrm{~m}^{3} \mathrm{~s}^{-1}$ ) on the first day of the eruption followed by a low stable activity (less than $10 \mathrm{~m}^{3} \mathrm{~s}^{-1}$ ) (Coppola et al., 2017). The lava volume erupted during the first phase was $10.8 \pm 3.7 \mathrm{Mm}^{3}$ (Coppola et al., 2017). An increase in TADR marked the second phase, between September 11 and October 13, which erupted $22.2 \pm 7.7 \mathrm{Mm}^{3}$ of lava (Coppola et al., 2017). Three short-lived pulses of about two days were then recorded in the third, terminal phase from October 14 and involved a lava volume of $12.2 \pm 4.2$ $\mathrm{Mm}^{3}$ (Coppola et al., 2017). A notable feature of the eruption was chemical zonation. Indeed, a progressive increase of the $\mathrm{MgO}$ magma content during the third phase may correspond to an evolution from cold degassed magma in the early phase to mafic gas-rich melts later (Sundermeyer et al., 2019).

\subsubsection{February 2019}

The 18 February eruption was located at Piton Madoré on the East flank of the Dolomieu crater. An initial lava effusion rate of $16 \mathrm{~m}^{3} \mathrm{~s}^{-1}$ increased to $25-50 \mathrm{~m}^{3}$ $\mathrm{s}^{-1}$ on March 7, associated with the opening of a new E-W trending fissure on March 7. Six new vents were formed along this fissure. These were active from 9 
to 10 March feeding lava fountains reaching $100 \mathrm{~m}$ (Figure 1b), lava flows and strong $\mathrm{SO}_{2}$ emissions (OVPF - Monthly Bulletin, 2019).

\subsubsection{April 2020}

The 2-6 April 2020 eruption occurred within the Enclos Fouque on the eastern flank of the Dolomieu crater. Surface activity was characterized by lava fountains up to $30 \mathrm{~m}$ in height and lava flows. On April 4, the seismicity increased until April 6 when the eruption stopped abruptly. Between April 4 to 6, large quantities of Pele's hair were emitted. Lava effusion rates reached an estimated maximum of $30 \mathrm{~m}^{3} \mathrm{~s}^{-1}$, but there are large uncertainties because of bad weather and the lock-down which limited field observations (Peltier et al., 2020).

a.

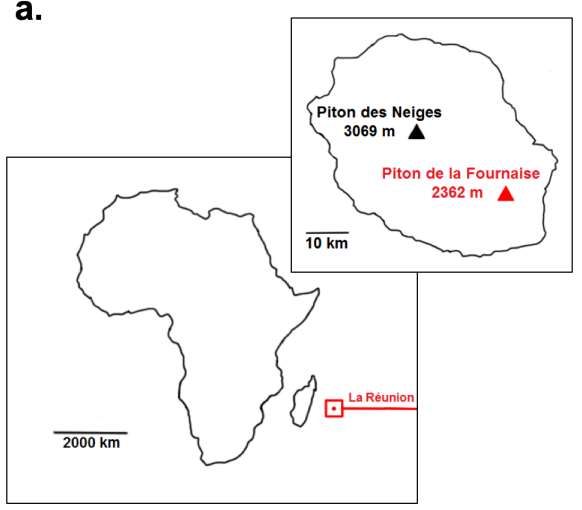

b.

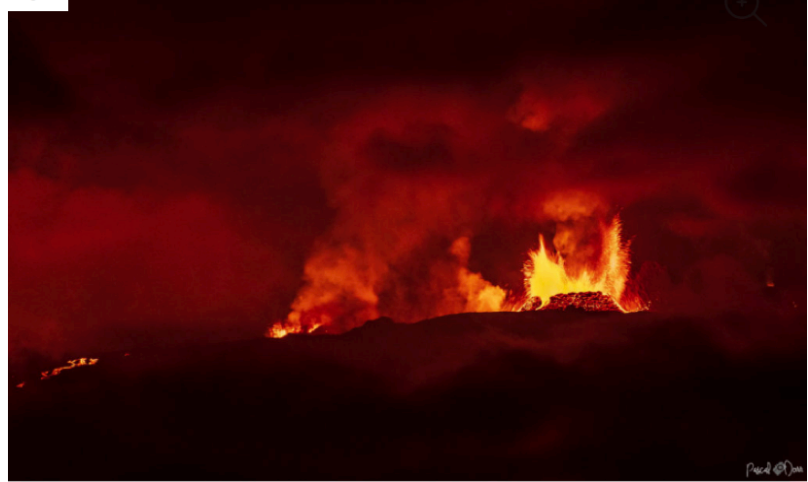

C.

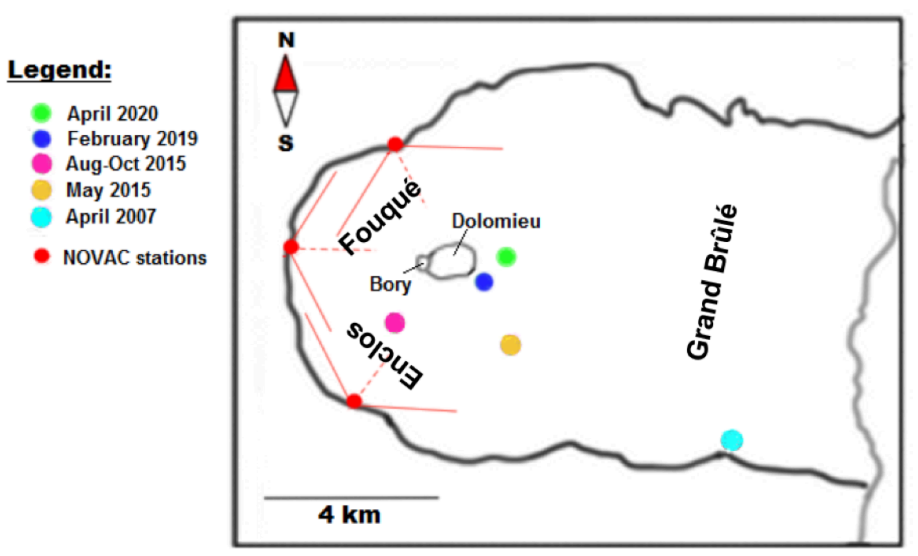

Figure 1: (a) Location of La Réunion Island. Piton de la Fournaise volcano is situated on the east side of Piton des Neiges volcano. (b) 18 , February 2019 eruption at Piton de la Fournaise volcano (La Réunion, FRANCE) (Photo courtesy: Pascal Dorr). (c) Location of the three NOVAC stations at Piton de la Fournaise and the location of the eruptions studied here. 


\section{Methodology}

As part of my first year Master's project at Michigan Technical University, I processed OMI, OMPS and TROPOMI for all eruptions at Piton de la Fournaise since 2004, deriving and comparing $\mathrm{SO}_{2}$ fluxes. Appendix 1 gives the time-series of the $\mathrm{SO}_{2}$ emissions of the selected eruptions now used for this second stage of the research.

In this study, TADR data, as acquired for the MODVOLC and MIROVA systems and estimated from manual processing of the MODIS images, was added. By integrating these data through an eruption, the cumulative lava volume can be determined and compared to field observations, assuming the latter are the most accurate, to validate the satellite-based retrievals. In addition, the total $\mathrm{SO}_{2}$ emission for each eruption has been estimated for a range of potential sulfur (S) contents within melt inclusions and matrix glass using a petrological approach. An inverse approach is also used to estimate the daily pre-eruptive magmatic sulfur content during the eruption by fixing the sulfur content within the matrix as well as the magma, allowing expected $\mathrm{SO}_{2}$ masses to be estimated from the satellitederived masses.

\subsection{Data acquisition}

\subsubsection{Tropospheric $\mathrm{SO}_{2}$ concentration measured from space}

To create the database, we use daily $\mathrm{SO}_{2}$ data acquired by the UV OMI, OMPS and TROPOMI sensors. The $\mathrm{SO}_{2}$ emission data are available at the following link: https://so2.gsfc.nasa.gov/, which clusters data from the three instruments. A summary of the main features for each instrument is available in Table 1.

\subsubsection{The Ozone Monitoring Instrument}

OMI is a hyperspectral UV and visible (VIS) spectrometer capable of detecting and measuring $\mathrm{SO}_{2}$ associated with volcanic eruptions and degassing from space. This instrument is aboard NASA's Aura satellite which is in a polar 
orbit with a local afternoon equator overpass at $13: 45$. It provides daily and nearly global coverage with a spatial resolution at nadir of $13 \times 24 \mathrm{~km}^{2}$. Measurements include ozone, $\mathrm{SO}_{2}$ and other trace gases such as $\mathrm{BrO}, \mathrm{HCHO}, \mathrm{NO}_{2}$ and $\mathrm{OClO}$. The UV-2 channel ranging from $270 \mathrm{~nm}$ to $365 \mathrm{~nm}$ is used to measure $\mathrm{SO}_{2}$ with a spectral resolution of $0.45 \mathrm{~nm}$ (Levelt et al , 2006).

\subsubsection{The Ozone Mapping and Profiler Suite Instrument}

Suomi NPP/OMPS is a nadir-viewing hyperspectral instrument measuring backscattered UV radiance with a spectral resolution of $1 \mathrm{~nm}$. It is situated in a low Earth orbit, with a local ascending equator overpass at 13:30. OMPS provides daily global coverage with a nadir pixel size of $50 \times 50 \mathrm{~km}^{2}$. Using a single detector array to cover $310 \mathrm{~nm}$, the OMPS instrument is suitable for $\mathrm{SO}_{2}$ measurements (Carn et al., 2015; Flynn et al., 2014; Yang et al., 2013).

\subsubsection{The Tropospheric Monitoring Instrument}

The Sentinel-5 Precursor satellite, also known as Sentinel-5P, carries only one instrument: TROPOMI. This instrument has four hyperspectral channels covering the UV to short-wave infrared (SWIR). The TROPOMI channel from 310$405 \mathrm{~nm}$, is used for $\mathrm{SO}_{2}$ retrievals and has a spectral resolution of $0.54 \mathrm{~nm}$. The Sentinel-5P spacecraft follows a polar orbit with a local equator crossing at 13:30 (ascending node). With a spatial resolution of $7 \times 3.5 \mathrm{~km}^{2}$, TROPOMI provides daily information with higher spatial resolution than the OMI and OMPS instruments (Veefkind et al , 2012).

Table 1: Summary of the main features of the Ozone Monitoring Instrument (OMI), Ozone Mapping and Profiler Suite (OMPS) and Tropospheric Monitoring Instrument (TROPOMI) instruments used in this study.

\begin{tabular}{|c|c|c|c|c|}
\hline Name & $\begin{array}{c}\text { Nadir spatial } \\
\text { resolution }\end{array}$ & Launch year & Spectral range & $\begin{array}{c}\text { Overpass time } \\
\text { (ascending node) }\end{array}$ \\
\hline OMI & $13 \times 24 \mathrm{~km}^{2}$ & 2004 & $\begin{array}{c}270-500 \mathrm{~nm} \\
(\mathrm{UV} / \mathrm{VIS})\end{array}$ & $\sim 13: 45$ \\
\hline OMPS & $50 \times 50 \mathrm{~km}^{2}$ & 2011 & $\begin{array}{c}310 \mathrm{~nm} \\
(\mathrm{UV})\end{array}$ & $\sim 13: 30$ \\
\hline TROPOMI & $7 \times 3.5 \mathrm{~km}^{2}$ & 2017 & $\begin{array}{c}310 \mathrm{~nm}-405 \mathrm{~nm} \\
(\mathrm{UV})\end{array}$ & $\sim 13: 30$ \\
\hline
\end{tabular}




\subsubsection{NOVAC network}

We also used ground-based $\mathrm{SO}_{2}$ data from a Network for Observation of Volcanic and Atmospheric Change (NOVAC) network operated by the Observatoire Volcanologique du Piton de la Fournaise (OVPF). This network integrates three stations deployed at distances of 4 to $6 \mathrm{~km} \mathrm{~W}$ of the Dolomieu crater (Figure 1c) to monitor $\mathrm{SO}_{2}$ emissions since the April 2007 eruption. These stations cover plumes transported north, west or south from the volcano. NOVAC measurements involve acquiring UV spectra $(280-420 \mathrm{~nm})$ from the sky over a cross-section of the atmosphere. The spectra obtained are analyzed using the Differential Optical Absorption Spectroscopy (DOAS) technique (Galle et al., 2010). However, the quality of the measurements depends on the wind direction, the magnitude of the eruption as well as the vent location. During weak eruptions, the plumes tend to be not covered by the stations installed on the Dolomieu crater's rim, leading to underestimation of $\mathrm{SO}_{2}$ emissions. Problems related to instrument saturation may also result in underestimated emissions. Also, the NOVAC stations are not well-situated to detect gas emissions from eruptions occurring on the East flank of the Dolomieu crater. Indeed, the vents may be hidden from the stations' field of view, leading to underestimated $\mathrm{SO}_{2}$ emissions (Figure 1c).

\subsubsection{MODIS data processing}

The TADRs for Piton de la Fournaise eruptions were acquired from two automated systems: MIROVA and MODVOLC. For the MODVOLC approach, the data are publicly available on the following website: http://modis. higp.hawaii.edu/. MIROVA data were provided by the University of Turin (Diego Coppola, personal communication, 04/12/2020). Both MODVOLC and MIROVA use MODIS Level 1b data collected from NASA's Terra and Aqua satellites (Coppola et al., 2016; Wright et al., 2002). Terra and Aqua MODIS acquire data in 36 spectral bands ranging from 0.4 to $14.4 \mu \mathrm{m}$ and provide global coverage every one to two days following the EOS orbit. The bands of interest (see below) have a nominal resolution of 1 $\mathrm{km}$ at nadir (Hook et al., 2001). Our goal was to compare the TADRs derived from 
MODVOLC and MIROVA and to validate the TADRs using manual analysis of MODIS L1b data. Hence the raw L1b MODIS radiance data were downloaded in order to manually select the hot spots and background pixels using the ENVI software. As part of this, spectral radiances were extracted from four spectral bands of interest:

- Radiance of Band 21 centered at $3.959 \mu \mathrm{m}$ (MIR channel: low gain)

- Radiance of Band 22 centered at $3.959 \mu \mathrm{m}$ (MIR channel: high gain)

- Radiance of Band 31 centered at $11.03 \mu \mathrm{m}$ (TIR channel)

- Radiance of Band 32 centered at $12.02 \mu \mathrm{m}$ (TIR channel)

Following pixel selection, the pixel spectral radiances were corrected for surface emissivity, atmospheric transmission, atmospheric emission and surface reflection effects using the following equation:

$$
L\left(\lambda, T_{S}\right)=\frac{L\left(\lambda, T^{*}\right)-L_{u}(\lambda)}{\varepsilon_{\lambda} \tau_{\lambda}}
$$

Where, $L$ is the Planck function, $L\left(\lambda, T_{S}\right)$ is the surface radiance for a surface at temperature $T_{S}$ measured at wavelength $\lambda, L\left(\lambda, T^{*}\right)$ is the at-sensor radiance, $\varepsilon_{\lambda}$ is the spectral emissivity, $\tau_{\lambda}$ is the atmospheric spectral transmissivity and $L_{u}(\lambda)$ is the atmospheric upwelling radiance. The three last parameters are obtained using MODTRAN software (Barsi et al., 2003). Further details of the procedure are given in "Thermal Remote Sensing of Active Volcanoes: A User's Manual" (Harris, 2013b).

The most important factor is saturation, which happens when the amount of emitted radiance that the MODIS sensor can detect is exceeded. To determine the pixel fraction occupied by a hot target necessary to saturate the different bands, Eq (2) has been used (Harris, 2013a):

$$
p=\frac{L\left(T_{s a t}\right)-L\left(T_{b}\right)}{L\left(T_{h o t}\right)-L\left(T_{b}\right)}
$$

Where $L\left(T_{b}\right)$ is the background radiance for the cold surface at temperature 
$T_{b}$ and $L\left(T_{h o t}\right)$ is the radiance of the hot spot. For a given hot spot and background temperature, we are able to determine $p$, the pixel fraction needed to reach the saturation level of the sensor, $L\left(T_{\text {sat }}\right)-T_{\text {sat }}$ being the saturation temperature. The saturation temperature has been fixed at $60^{\circ} \mathrm{C}, 180^{\circ} \mathrm{C}$ and $130^{\circ} \mathrm{C}$ for Bands 22,21 and $31+32$, respectively. Once the saturation point is reached, only single value is recorded, so even if the area and temperature of the hot spot increases the brightness temperature will remain the same. Thus, any derived value (e.g., TADR) using saturated values will provide a minimum limit on the value, where Figure 2 shows the upper limit of the size/temperature of the feature that can be measured before this occurs for a $T_{b}$ of $25^{\circ} \mathrm{C}$. By taking a $1 \mathrm{~km}^{2}$ pixel (e.g., at nadir) and a hot spot temperature of $500^{\circ} \mathrm{C}$, Figure 2 illustrates that only a small portion of pixel $(3.50 \%)$ is needed to complete a saturation in the MIR compare to the ones in TIR $(12.35-13.30 \%)$. It is also important to point out that despite the Band 22 reaches the saturation level for a much smaller area $\left(1200 \mathrm{~m}^{2}\right)$ than Band $21\left(35000 \mathrm{~m}^{2}\right)$ despite same spectral range.

\subsection{Estimation of lava discharge rate from MODIS data}

Two methods have been applied to estimate TADR. The first one is a linear relationship directly relating the satellite-derived spectral radiance and TADR:

$$
T A D R=c \times L_{\lambda-f l o w}
$$

Where $L_{\lambda \text {-flow }}$ is the hot spot radiance minus the background radiance summed for all relevant MODIS pixels and $c$ is a constant equal to 0.128 as determined during the May-July 2003 eruption at Piton de la Fournaise (Coppola et al., 2009; Harris and Ripepe 2007). The second way to obtain the TADR is to utilize a thermodynamic approach (Harris et al., 1998; Harris and Baloga, 2009).

$$
T A D R=\frac{\sigma \varepsilon\left(T_{c}^{4}-T_{a}^{4}\right)+h_{c}\left(T_{c}-T_{a}\right)}{\rho_{m}\left(c_{p} \Delta T+\varphi c_{L}\right)} \times A_{\text {lava }}
$$


Where $\sigma$ is the Stefan Boltzmann constant $\left(5.67 \times 10^{-8} \mathrm{~W} \mathrm{~m}^{-2} \mathrm{~K}^{-4}\right), h_{c}$ is the convective heat transfer coefficient (10 $\mathrm{W} \mathrm{m}^{-2} \mathrm{~K}^{-1}$, (Harris, 2013b)), $T_{c}$ and $T_{a}$ are the temperature $(\mathrm{K})$ of the lava surface and background, respectively, $\rho_{m}$ is the bulk density of the lava $\left(\mathrm{kg} \mathrm{m}^{-3}\right), c_{p}$ is the bulk specific heat $\left(\mathrm{J} \mathrm{kg}^{-1} \mathrm{~K}^{-1}\right), c_{L}$ is the latent heat of crystallization $\left(\mathrm{J} \mathrm{kg}^{-1}\right), \Delta T$ is the cooling range between the vent and the flow front (Pieri et al., 1984) (K), $\varphi$ is the crystallization in cooling through $\Delta T$ and $A_{\text {lava }}$ is the active lava area $\left(\mathrm{m}^{2}\right)$. Eq (4) can be reduced to a linear relationship, where $\frac{m}{b}$ is an empirical parameter that converts $A_{\text {lava }}$ to TADR:

$$
T A D R=\frac{m}{b} \times A_{\text {lava }}
$$

The constants $m$ and $b$ lump together all the assumed values that are the same for all measurements (Wright et al., 2001, Harris et al., 2007), where $m=$ $2.07 \times 10^{4}$ and $b=6.12 \times 10^{7}$. Using a value of $3.38 \times 10^{-4}$ for $\frac{m}{b}$, Eq (5) provides nearly the same results as the direct conversion from spectral radiance (Eq (3)), except for the April 2007 eruption where $a \frac{m}{b}$ value of $3.53 \times 10^{-4}$ gives the best fit. In addition, following Coppola et al., (2009), for the April 2007 eruption, the maximum TADR is increased by $30 \%$ due to the flux lost to the ocean. By integrating TADR through the whole duration of the eruption, we acquire the volume of lava erupted (Coppola et al., 2013; Harris et al., 2001; Harris et al., 1997).

\subsection{Conversion of $\mathrm{SO}_{2}$ to lava masses}

\subsubsection{Petrologic method}

The petrological approach assumes that melt inclusions trapped within olivine phenocrysts in the magma chamber represent the initial volatile contents of the melt. We assume that there are no contributions from independent fluid and solid phases, and that no volatile degassing occurred prior to melt inclusion entrapment. As a consequence, the source of the degassed $S$ is the melt phase of 
the magma. The petrologic method, therefore, estimates the mass of $\mathrm{SO}_{2}\left(M_{\mathrm{SO}_{2}}\right)$ released as:

$M_{S O_{2}}=\frac{\left[\rho_{m} \times V_{\text {lava }} \times\left(1-\phi-\varepsilon_{c r x}\right)\right] \times 2 \times\left(c_{S}^{M I}-c_{S}^{\text {matrix }}\right)}{10^{6}}=\alpha \times\left(c_{S}^{M I}-c_{S}^{\text {matrix }}\right)$

(6)

Where $V_{\text {lava }}$ is the total volume of lava emitted during the eruption $\left(\mathrm{m}^{3}-\right.$ here the MIROVA data has been used, Table 3$), c_{S}^{M I}$ and $c_{S}^{\text {matrix }}$ are the sulphur concentration recorded in the melt inclusion and the matrix, respectively, $\rho_{m}$ is the bulk melt density assuming a melt density of $2940 \mathrm{~kg} \mathrm{~m}^{-3}$ (Andrea Di Muro, personal communication, 16/12/2020), $\phi$ is the vesicularity, $\varepsilon_{c r x}$ is the average volume fraction of phenocrysts in the magma (Self et al., 2004), and $\alpha$ is a constant clustering all the lava parameters. Table 2 summarizes the crystal fraction, vesicularity and the bulk density data used for the studied eruptions.

\subsubsection{Petrologic method including a time parameter}

According to petrological analysis, $c_{S}^{\text {matrix }}$ can be fixed at $160 \pm 60 \mathrm{ppm}$ during high intensity phases (e.g., lava fountains). This residual value can increase up to $230 \pm 30$ ppm during periods of low degassing (Di Muro et al., 2015). Knowing this parameter and, the daily $\mathrm{SO}_{2}$ and lava masses detected from space, Eq (6) may be arranged as:

$$
c_{S}^{M I}=c_{S}^{\text {matrix }}+\frac{M_{S O_{2}}}{\alpha}
$$

The vesicularity and crystallinity, included in the $\alpha$ parameter vary during eruptions (see Table 2), and so are adjusted accordingly. In this way, a time series of the pre-eruptive sulfur content can be estimated. 
Table 2: Summary of petrologic method data used to estimate the sulfur content and $\mathrm{SO}_{2}$ mass, where $\varepsilon_{c r x}$ is the crystallinity and $\phi$ the vesicularity (http://wwwobs.univbpclermont.fr/SO/televolc/dynvolc/)

\begin{tabular}{|c|c|c|c|c|c|}
\hline Eruption & $\boldsymbol{\Phi}(\mathbf{\%})$ & $\begin{array}{c}\text { Range } \boldsymbol{\varepsilon}_{\text {crx }} \\
(\mathbf{\%})\end{array}$ & $\begin{array}{c}\text { Average } \boldsymbol{\varepsilon}_{\text {crx }} \\
(\mathbf{\%})\end{array}$ & $\begin{array}{c}\text { Bulk density } \\
\left(\mathbf{k g ~ m}^{-3} \mathbf{)}\right.\end{array}$ & $\begin{array}{c}\text { Average density } \\
\left(\mathbf{k g ~ m}^{-3} \mathbf{)}\right.\end{array}$ \\
\hline April 2020 & 52 & $2.83-9.16$ & 4.90 & $1142-1331$ & 1267 \\
\hline February 2019 & 52 & $2.14-41.13$ & 12.00 & $202-1348$ & 1057 \\
\hline Aug-Oct 2015 & 52 & $2.00-10.70$ & 5.50 & $1096-1354$ & 1249 \\
\hline May 2015 & 52 & $2.40-3.00$ & 2.70 & $1327-1342$ & 1333 \\
\hline April 2007 & 40 & $4.70-53.30$ & 44.20 & $1625-196$ & 464 \\
\hline
\end{tabular}

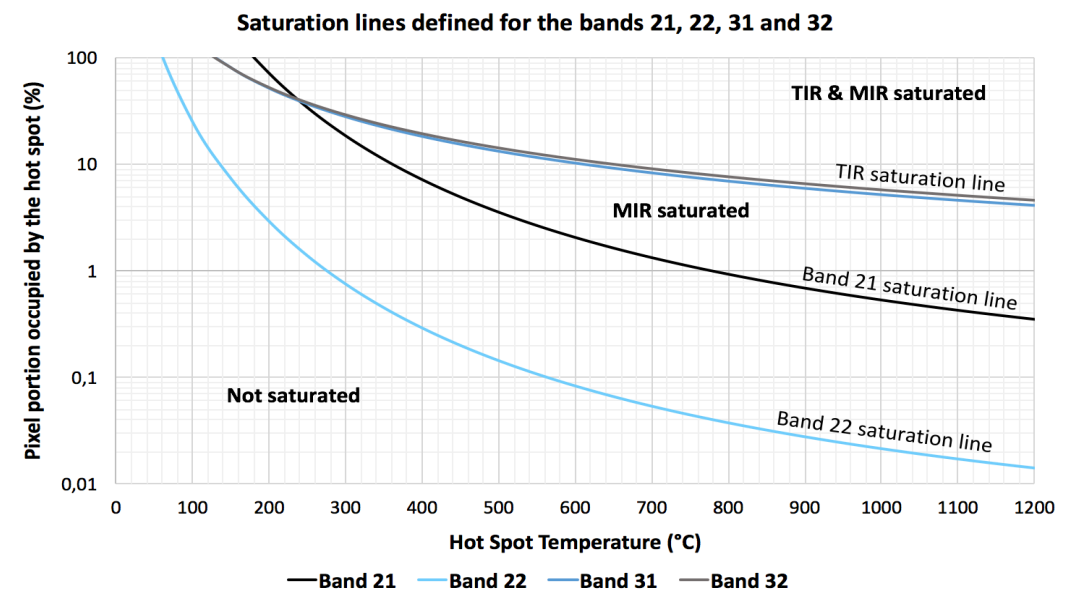

Figure 2: Temperature and size of a subpixel hot spot necessary to saturate the MIR and TIR spectral bands of MODIS given a background temperature of $25^{\circ} \mathrm{C}$.
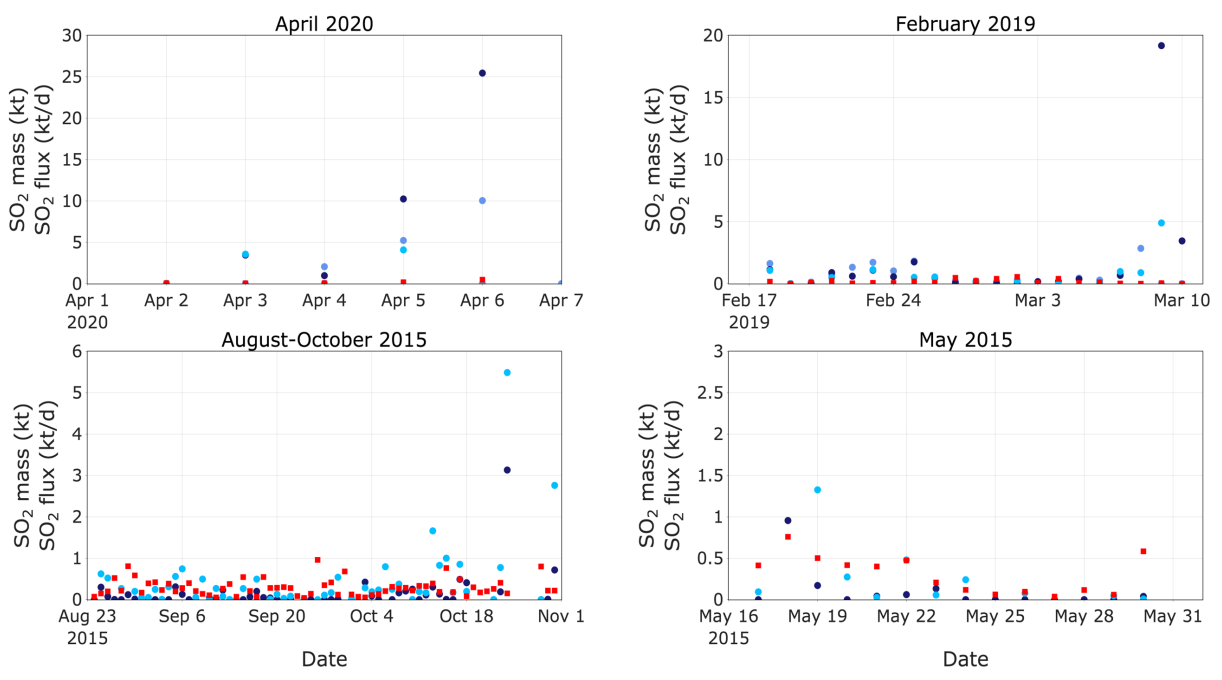

-TROPOMI - OMPS - OMI - NOVAC

Figure 3: Time series of TROPOMI, OMPS and $\mathrm{OMI} \mathrm{SO}$ masses compared to ground-based $\mathrm{SO}_{2}$ fluxes from the NOVAC network for the eruptions of interest. 


\section{Results}

\subsection{Comparisons with NOVAC}

The $\mathrm{SO}_{2}$ masses calculated from the satellite data are first compared with the $\mathrm{SO}_{2}$ flux measured from ground-based NOVAC stations for the five selected eruptions (Figure 3). Even if there are differences, Figure 3 shows good agreement for the eruptions occurring in 2015, where the same trends are apparent in all datasets (OMPS, OMI and NOVAC). However, for the February 2019 and April 2020 eruptions, the NOVAC fluxes are much lower than the satellite measurements. We note that the location of the vents for these eruptions were hidden from the NOVAC field of view (Figure 1c) leading to inaccurate groundbased data as part of the signal (plume) is missing from the instrument view. On the other hand, the discrepancy between the UV satellite instruments may result from their different spatial resolution leading to either an under- or overestimation (Table 1).

It is important to note that there are uncertainties on all the datasets: groundbased $\mathrm{SO}_{2}$ fluxes depend strongly on wind direction and speed as well as the plume altitude. An assumption is also made on the plume altitude for the satellite $\mathrm{SO}_{2}$ retrievals.

\subsection{MODIS analysis}

The MODIS data allowed us to estimate the TADR and obtain the effusive trend by considering only the data acquired during good weather conditions. Also, a comparison can be made between the lava volume obtained by the integrated MODIS-derived TADR with the one measured in the field. For both discharge rates and volumes, the estimations correspond to those derived from the MIROVA and MODVOLC automatic systems, and the Manual method. Note that for the Manual approach, an estimation without the atmospheric correction was also calculated too. Results reveal that the TADR estimations using the raw data from the manual approach give lower values. As the MIROVA and MODVOLC systems do not 
consider the atmospheric correction, this analysis suggests that these two methods overestimate the lava discharge rates. The comparison with the manual method applied to the uncorrected data bear this out as they are similar, meaning that overestimation results from excess spectral radiance contributed by the atmosphere, which may be heated by the underlying lava and therefore highly emissive. To simplify, in the following sections, we will only consider the first manual approach $(\mathrm{Eq}(3))$ that has been corrected for the atmospheric parameters (aka: Manual). The reader will find all figures (i.e., all comparisons) in Appendix 2.

\subsubsection{April 2007}

The April 2007 eruption produced a total of $185 \mathrm{Mm}^{3}$ of lava (Derrien, 2019). As the eruption was very intense, instruments were saturated, there being between 3 and 10 saturated pixels per image (i.e., $17-60 \%$ of the anomalous pixels) so that minimum bounds are all that can be given. This assumption has been also selected for the three other methods. Appendix 2a shows a peak on April 5 that has been recorded by all the methods even if there is a significant discrepancy between the MIROVA estimation $\left(200 \mathrm{~m}^{3} \mathrm{~s}^{-1}\right)$ and the other ones (Manual: $48 \mathrm{~m}^{3} \mathrm{~s}^{-1}$, MODVOLC: $51 \mathrm{~m}^{3} \mathrm{~s}^{-1}$ ). This peak occurred one day before the collapse of the Dolomieu crater. One may notice that the lava discharge rate is nearly equal to zero on April 6. On the MODIS image acquired on that day, the volcanic plume, clearly visible, precludes detection of any hot spots; this being a form of cloud contamination. A second peak is recorded after the next and smaller collapse of the Dolomieu crater occurring on April 12. TADR estimation from the MODVOLC system $\left(78 \mathrm{~m}^{3} \mathrm{~s}^{-1}\right)$, MIROVA $\left(70 \mathrm{~m}^{3} \mathrm{~s}^{-1}\right)$ and the Manual method $\left(73 \mathrm{~m}^{3} \mathrm{~s}^{-1}\right)$ are in good agreement. The next few days are marked by a decline in the discharge rates, occasionally interrupted by minor fluctuations at the end of April (Appendix $2 a)$. Assuming that the field volume is the accurate one, the manual and MODVOLC approaches largely underestimate the volume (Table 3). However, MIROVA gives a higher estimation closer to what we expect. 


\subsubsection{May 2015}

This event was characterized by a high TADR of $30 \mathrm{~m}^{3} \mathrm{~s}^{-1}$ on May 17-18 followed by an exponential decrease (Figure 4b). Despite a good agreement between the approaches, we observe a significant discrepancy on May 17 (MODVOLC: $29 \mathrm{~m}^{3} \mathrm{~s}^{-1}$, MIROVA: $25 \mathrm{~m}^{3} \mathrm{~s}^{-1}$, Manual: $14 \mathrm{~m}^{3} \mathrm{~s}^{-1}$ ). Regarding the cumulative volume, the high lava discharge rates from MODVOLC lead to the highest cumulative volume $\left(8.9 \mathrm{Mm}^{3}\right)$, greater than MIROVA $\left(6 \mathrm{Mm}^{3}\right)$ which matches with the lava volume measured in the field $\left(5.73 \mathrm{Mm}^{3}\right)($ Table 3 , Appendix $2 b)$.

\subsubsection{August-October 2015}

Figure $4 a$ shows a high TADRS of $50 \mathrm{~m}^{3} \mathrm{~s}^{-1}$ at the beginning of the eruption. The activity started on August 24 with high TADRs, but some differences (MIROVA: $50 \mathrm{~m}^{3} \mathrm{~s}^{-1}$, Manual: $24 \mathrm{~m}^{3} \mathrm{~s}^{-1}$ ). Following this initial peak, TADRs remained nearly constant $\left(5-10 \mathrm{~m}^{3} \mathrm{~s}^{-1}\right.$ up to $13-20 \mathrm{~m}^{3} \mathrm{~s}^{-1}$ for MODVOLC data) during the second phase of the eruption from September 11 until October 16, where the last phase involves three final pulses each interrupted by 4 days of inactivity between each (Figure 4a). The first pulse on October 17 (MIROVA: 17 $\mathrm{m}^{3} \mathrm{~s}^{-1}$, Manual: $26 \mathrm{~m}^{3} \mathrm{~s}^{-1}$, MODVOLC: $46 \mathrm{~m}^{3} \mathrm{~s}^{-1}$ ) is followed by two eruptive pulses on October 23 (MIROVA: $21 \mathrm{~m}^{3} \mathrm{~s}^{-1}$, Manual: $37 \mathrm{~m}^{3} \mathrm{~s}^{-1}$, MODVOLC: $67 \mathrm{~m}^{3} \mathrm{~s}^{-1}$ ) and on October 30 (MIROVA: $17 \mathrm{~m}^{3} \mathrm{~s}^{-1}$, Manual: $27 \mathrm{~m}^{3} \mathrm{~s}^{-1}$, MODVOLC: $49 \mathrm{~m}^{3} \mathrm{~s}^{-1}$ ). Assuming that the field volume of $36.6 \mathrm{Mm}^{3}$ represents the true one, MIROVA and the first manual approaches provide nearly the same estimations (42.8 and 39.0 $\mathrm{Mm}^{3}$, respectively - Table 3). However, the MODVOLC algorithm overestimates the lava volume emitted $\left(73.3 \mathrm{Mm}^{3}\right)$ during the August-October eruption, an event that was particularly long-lived lasting 65 days allowing a cumulate of the overestimation and end up with a degree of overshoot. 


\subsubsection{February 2019}

For this eruption, TADR was steady over time and below $10 \mathrm{~m}^{3} \mathrm{~s}^{-1}$, except at the end when an increase in TADR to $37 \mathrm{~m}^{3} \mathrm{~s}^{-1}$ according to MIROVA is recorded (Appendix 2a). We see a peak at the end of the eruption that is not as high in the manually processed data than in the MIROVA data $\left(19 \mathrm{~m}^{3} \mathrm{~s}^{-1}\right.$ versus $37 \mathrm{~m}^{3} \mathrm{~s}^{-1}$ - Appendix 2a). In general, MODVOLC-derived values are much higher than all others, ranging from 9 to $31 \mathrm{~m}^{3} \mathrm{~s}^{-1}$. In addition, the MODVOLC system stopped detecting the hot spots after March 2. Hence, no estimation of TADR can be made for the end of February, thus missing the intense terminal phase of the eruption. Regarding the lava volume emitted during the eruption, MIROVA, and field estimations are alike, being $13.6 \mathrm{Mm}^{3}$ and $14.5 \mathrm{Mm}^{3}$, respectively (Table 3). However, the MODVOLC and manual approaches provide a cumulative volume that are also alike, but lower; being 11.2 and $9.8 \mathrm{Mm}^{3}$, respectively (Table 3). The gap between the manual method and the field volume may be explained by the low TADR estimations on March 7 to 10. In contrast, despite no hot spots detection from March 3, the MODVOLC system gives a closer lava volume with what we expect, mostly due to its systematic over-estimation.

\subsubsection{April 2020}

Only three detections were made by MODVOLC. This was due to the extremely cloudy conditions during this eruption, leading to poor detection rates. We see two TADR peaks on April 4 and 5 (Appendix 2a). Although MIROVA and manual values are similar (a difference of $6 \mathrm{~m}^{3} \mathrm{~s}^{-1}$ ), MIROVA estimates a TADR on April 5 (22 against $8 \mathrm{~m}^{3} \mathrm{~s}^{-1}$ for Manual). Note that large quantities of Pele's hair were emitted during this time, highlighting intense activity. Concerning the cumulative volume, the bad weather made it challenging to detect thermal anomalies, leading to a significant underestimation, where we obtain a volume that is between 2 and $5 \mathrm{Mm}^{3}$ less than the bulk field volume (Table 3 ). 


\subsubsection{Thermally-derived TADR data: Sum up}

Although consistent in terms of trend, there is some divergence in absolute values derived from each approach (Appendix 2). Discrepancies come from the limits in terms of detection by an automatic systems' algorithms as well as saturation problems (

Table 4), plus human error regarding the manual method. Also, the MIROVA and MODVOLC systems do not correct for emissivity, atmosphere and surface reflection. Hence, the actual surface leaving spectral radiances are overestimated by $25 \%$ due to atmospheric absorption. In general, MODVOLC seems to overestimate TADR but, we obtain a good correlation between MIROVA and Manual data (Figure 5).

By integrating TADR through time, all methods provide similar cumulative lava volumes. However, assuming that the field volume corresponds to the real one, one may observe that in April 2020 and April 2007, all approaches significantly underestimate the lava volume emitted during the eruption (Table 3). This is due to bad weather and/or saturation of the sensor which cause data loss and under-estimate. However, the total lava volumes for year 2015 are in good agreement with the ground volume, except the ones given by the MODVOLC system which overestimates despite missing days (

Table 4). We address the cause for this in the discussion.

Table 3: Estimated total volumes of erupted lava $\left(\mathrm{Mm}^{3}\right)$ from field measurements, the MIROVA and MODVOLC systems, and manually. Manual DC corresponds to the direct conversion from spectral radiance and Manual TA is the thermodynamic approach.

\begin{tabular}{|c|c|c|c|c|c|}
\hline \multirow{2}{*}{ Eruption } & \multicolumn{5}{|c|}{ Cumulative Lava Volume $\left(\mathbf{M m}^{3}\right)$} \\
\cline { 2 - 6 } & Field & MIROVA & MODVOLC & Manual DC & Manual TA \\
\hline $\begin{array}{c}\text { April } \\
\mathbf{2 0 2 0}\end{array}$ & $6-10^{*}$ & $2.9 \pm 1.0$ & $3.9 \pm 2.0$ & $1.8 \pm 0.6$ & $2.3 \pm 1.1$ \\
\hline $\begin{array}{c}\text { February } \\
\mathbf{2 0 1 9}\end{array}$ & $14.50^{* *}$ & $13.6 \pm 4.8$ & $11.2 \pm 3.6$ & $9.8 \pm 3.4$ & $9.4 \pm 4.7$ \\
\hline $\begin{array}{c}\text { Aug-Oct } \\
\mathbf{2 0 1 5}\end{array}$ & $36.56^{* * *}$ & $42.8 \pm 1.5$ & $79.3 \pm 23.8$ & $39.0 \pm 13.7$ & $36.2 \pm 18.1$ \\
\hline May 2015 & $5.73^{* * *}$ & $6.0 \pm 2.1$ & $8.9 \pm 2.7$ & $6.7 \pm 2.3$ & $6.2 \pm 3.1$ \\
\hline
\end{tabular}




\begin{tabular}{|c|c|c|c|c|c|}
\hline $\begin{array}{l}\text { April } \\
2007\end{array}$ & $185^{* * *}$ & $126.1 \pm 63.0$ & $48.9 \pm 24.4$ & $46.2 \pm 23.1$ & $52.2 \pm 26.1$ \\
\hline $\begin{array}{l}\text { (Peltier } \\
\text { Jolume }\end{array}$ & 20 & Volume, ${ }^{* *} \mathrm{Pr}$ & & Villeneuve, ${ }^{* *}$ & errien, 2019) \\
\hline
\end{tabular}
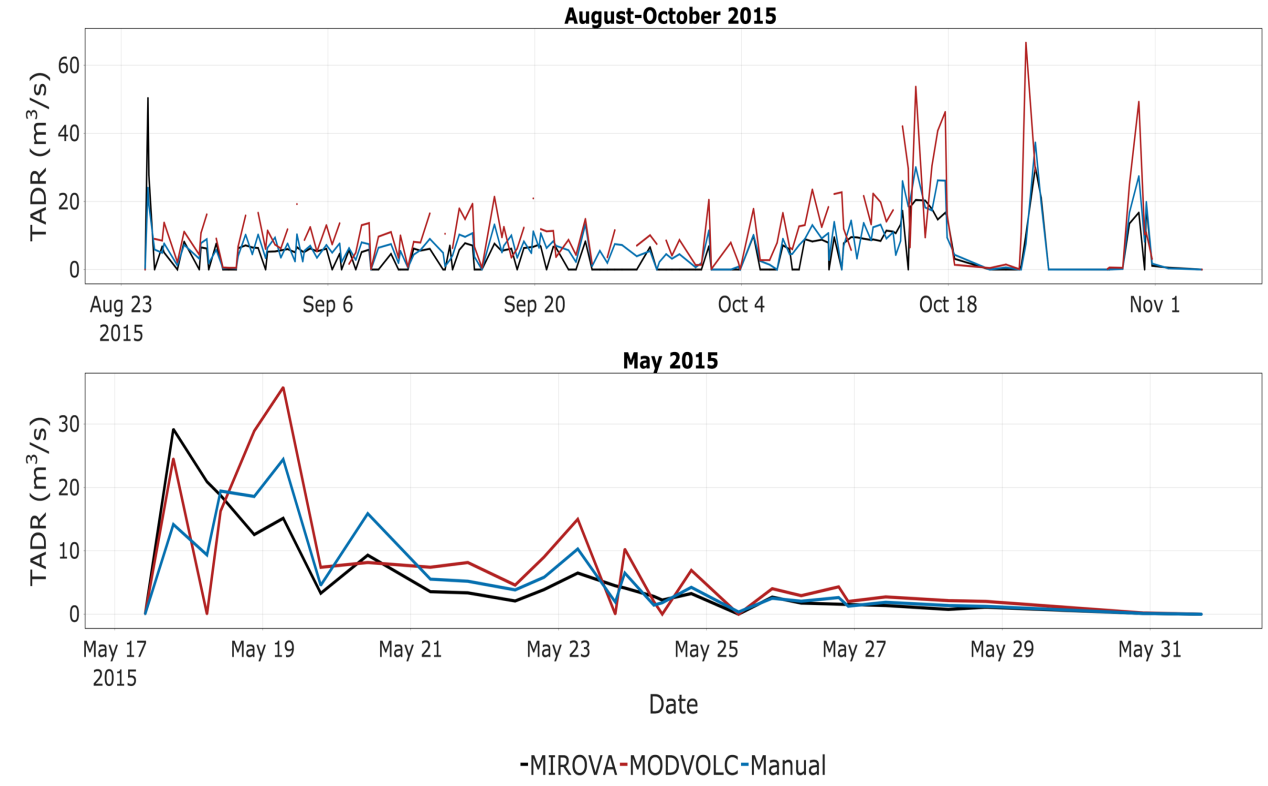

Figure 4: TADR for the following eruptions: (a) August-October 2015 and (b) May 2015. The estimations correspond to the MIROVA (black), MODVOLC (red) and Manual (blue) -based estimations.

Table 4: Summary of the total pixels for each eruptions counted by each method. Note that the MIROVA algorithm may resampled MODIS images into $1 \mathrm{~km}$ equal area pixels (e.g.: high zenith angle). Hence for some cases, one original MODIS pixel may be divided into several "MODISMIROVA" pixels. That explains the differences regarding the total pixels between MIROVA and the other approaches. "\# / \% pixels sat" = number / percentage of saturated pixel

\begin{tabular}{|c|c|c|c|c|c|c|c|c|c|}
\hline \multirow{2}{*}{ Eruption } & \multicolumn{3}{|c|}{ MODVOLC } & \multicolumn{3}{c|}{ MIROVA } & \multicolumn{3}{c|}{ MANUAL } \\
\cline { 2 - 10 } & $\begin{array}{c}\text { total } \\
\text { pixels }\end{array}$ & $\begin{array}{c}\text { \# pixels } \\
\text { sat }\end{array}$ & $\begin{array}{c}\% \text { pixel } \\
\text { sat }\end{array}$ & $\begin{array}{c}\text { total } \\
\text { pixels }\end{array}$ & $\begin{array}{c}\text { \# pixels } \\
\text { sat }\end{array}$ & $\begin{array}{c}\text { \% pixel } \\
\text { sat }\end{array}$ & $\begin{array}{c}\text { total } \\
\text { pixels }\end{array}$ & $\begin{array}{c}\text { \# pixels } \\
\text { sat }\end{array}$ & $\begin{array}{c}\% \text { pixel } \\
\text { sat }\end{array}$ \\
\hline $\begin{array}{c}\text { April } \\
\mathbf{2 0 2 0}\end{array}$ & 21 & 0 & 0.0 & 125 & 4 & 3.2 & 77 & 2 & 2.6 \\
\hline $\begin{array}{c}\text { February } \\
\mathbf{2 0 1 9}\end{array}$ & 93 & 1 & 1.1 & 423 & 5 & 1.2 & 158 & 1 & 0.6 \\
\hline $\begin{array}{c}\text { Aug-Oct } \\
\mathbf{2 0 1 5}\end{array}$ & 591 & 0 & 0.0 & 1642 & 0 & 0.0 & 675 & 1 & 0.2 \\
\hline $\begin{array}{c}\text { May } \\
\mathbf{2 0 1 5}\end{array}$ & 96 & 1 & 1.0 & 336 & 0 & 0.0 & 130 & 0 & 0.0 \\
\hline $\begin{array}{c}\text { April } \\
\mathbf{2 0 0 7}\end{array}$ & 204 & 107 & 52.5 & 730 & 380 & 52.1 & 409 & 190 & 46.5 \\
\hline
\end{tabular}



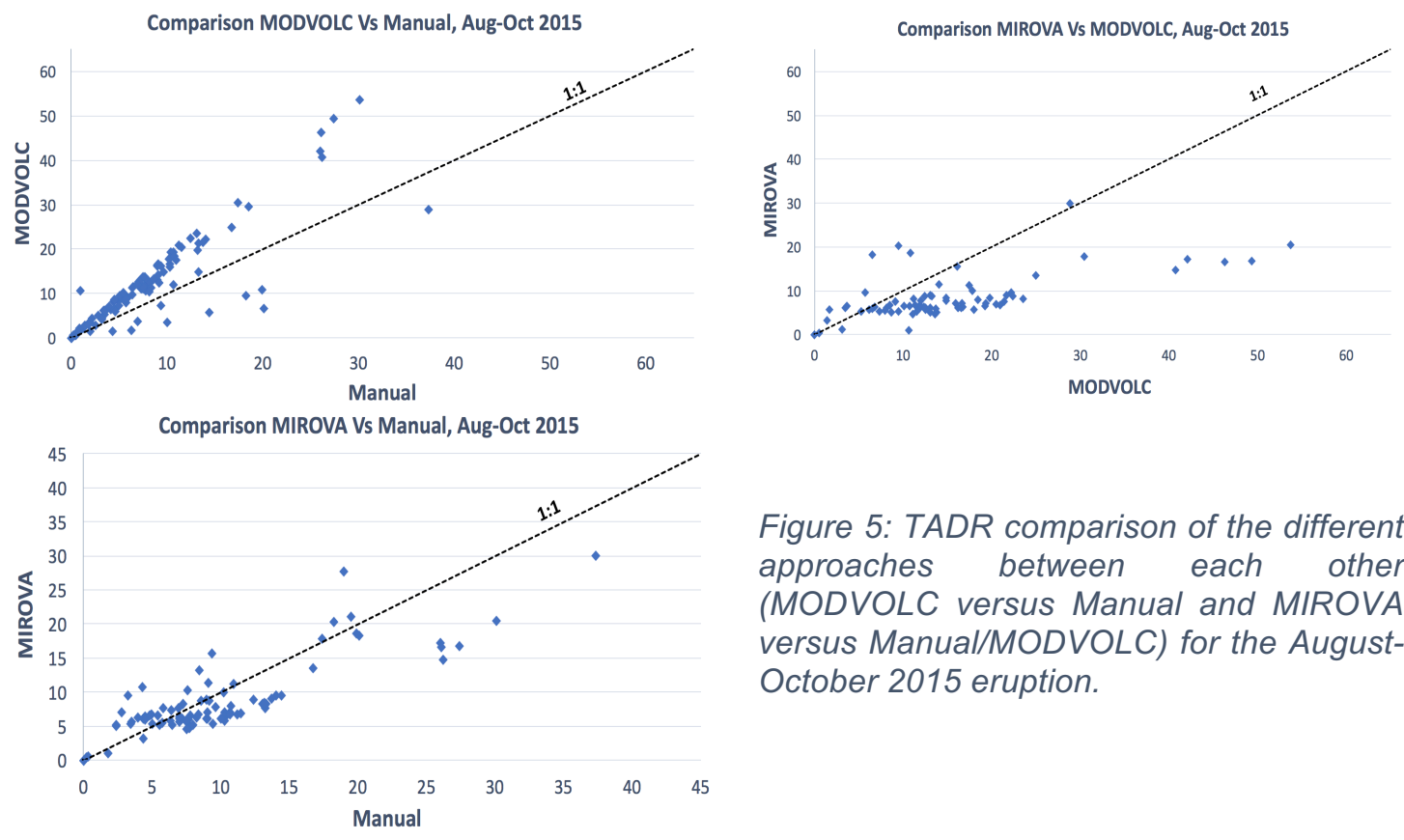

Figure 5: TADR comparison of the different approaches between each other (MODVOLC versus Manual and MIROVA versus Manual/MODVOLC) for the AugustOctober 2015 eruption.

\subsection{Magmatic sulfur content estimation}

\subsubsection{General analysis}

Figure 7 shows that the retrieved magmatic sulfur contents using a petrological approach and the erupted lava masses obtained from MODIS TIR satellite data are in good agreement with expected values for basaltic eruptions. Given pre-eruptive $S$ contents of between 100 and 400 ppm, estimated $\mathrm{SO}_{2}$ emissions for the May 2015 eruption are consistent with an eruption largely fed by degassed magma. Both OMI and OMPS indicate $\sim 200-500$ ppm of sulfur in melt inclusions (Figure 7d). Similar values are obtained for the August-October 2015 eruption using OMPS data. OMI data yield slightly higher values of $\sim 300-650 \mathrm{ppm}$ $S$ (Figure 7c) but, despite this slight difference, the estimated sulfur contents are in good agreement between the two sensors.

However, for the February 2019 eruption, the difference between the three satellite sensors is greater. Whereas TROPOMI and OMI indicate a similar range of magmatic sulfur content (300-800 ppm), but OMPS gives a higher range (800 to $1600 \mathrm{ppm}$ ), suggesting that fresh, undegassed magma was also involved in this eruption (Figure 7b). The situation is similar for the April 2020 eruption, where 
TROPOMI provides results around 2000 ppm and OMI between 900 and 1600 ppm (Figure 7a). Figure 7a does not show the OMPS results as no magmatic sulfur content values matched the total mass of $\mathrm{SO}_{2}$ detected by the sensor. The difference between TROPOMI and OMI may be ascribed to OMI data gaps, so that some eruption days were missed. On April 4 and 6, TROPOMI and OMPS measured 12.1 and $26.4 \mathrm{kt}$ of $\mathrm{SO}_{2}$ (Appendix 1), respectively, whereas OMI data gaps lead to an underestimation of the total $\mathrm{SO}_{2}$ emissions during the entire eruption. Note also that the lava volumes derived from the TADRs may be inaccurate as the weather conditions were not optimal for the April 2020 eruption. For the April 2007 eruption, all the $\mathrm{SO}_{2}$ masses estimated using the petrological method were lower than the $270 \mathrm{kt}$ of $\mathrm{SO}_{2}$ detected by the OMI sensor, indicating a possible sulfur "excess" during this eruption.

The average pre-eruptive $S$ content in melt inclusions obtained with the petrological method by fixing $c_{S}^{\text {matrix }}$ at 160 ppm during high flux phases or 230 ppm during low degassing may be too low. We expect higher values according to the measured $S$ within melt inclusions from petrological analysis (Figure 6). Indeed, the typical value for magma located in the shallow reservoir is around 1050 ppm. Note that deeper and enriched melts may have $c_{S}^{M I}$ values reaching $1250-$ 1600 ppm (Hibert et al., 2015).

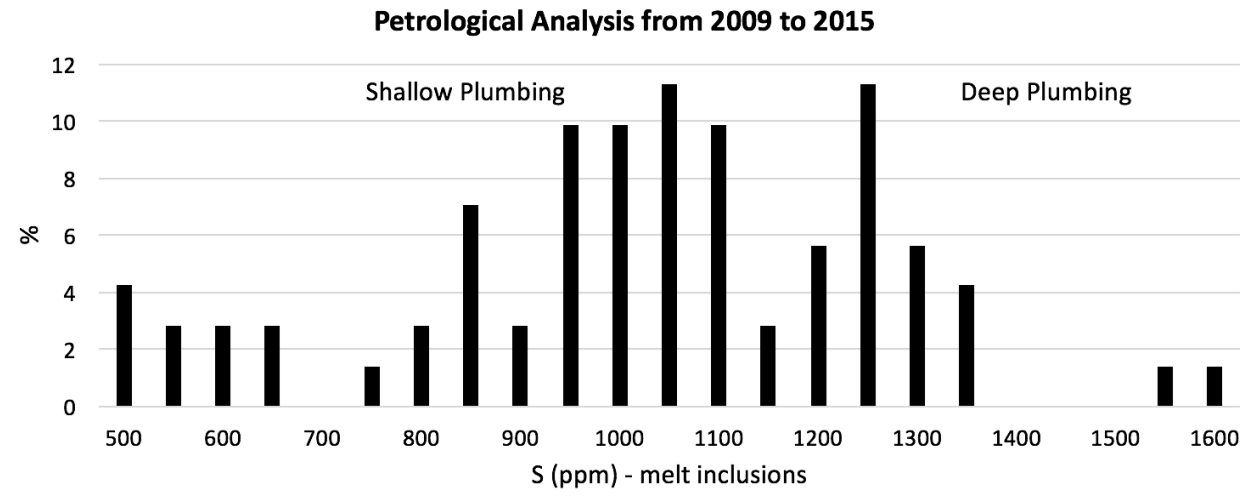

Figure 6: Petrological analysis of sulfur in melt inclusions from 2009 to 2015 (Di Muro et al., 2015). Inclusions having a sulfur content of 1050 are considered to come from the sea level reservoir. Those that have a higher sulfur content than 1250 ppm may be related to deeper mafic inputs. 

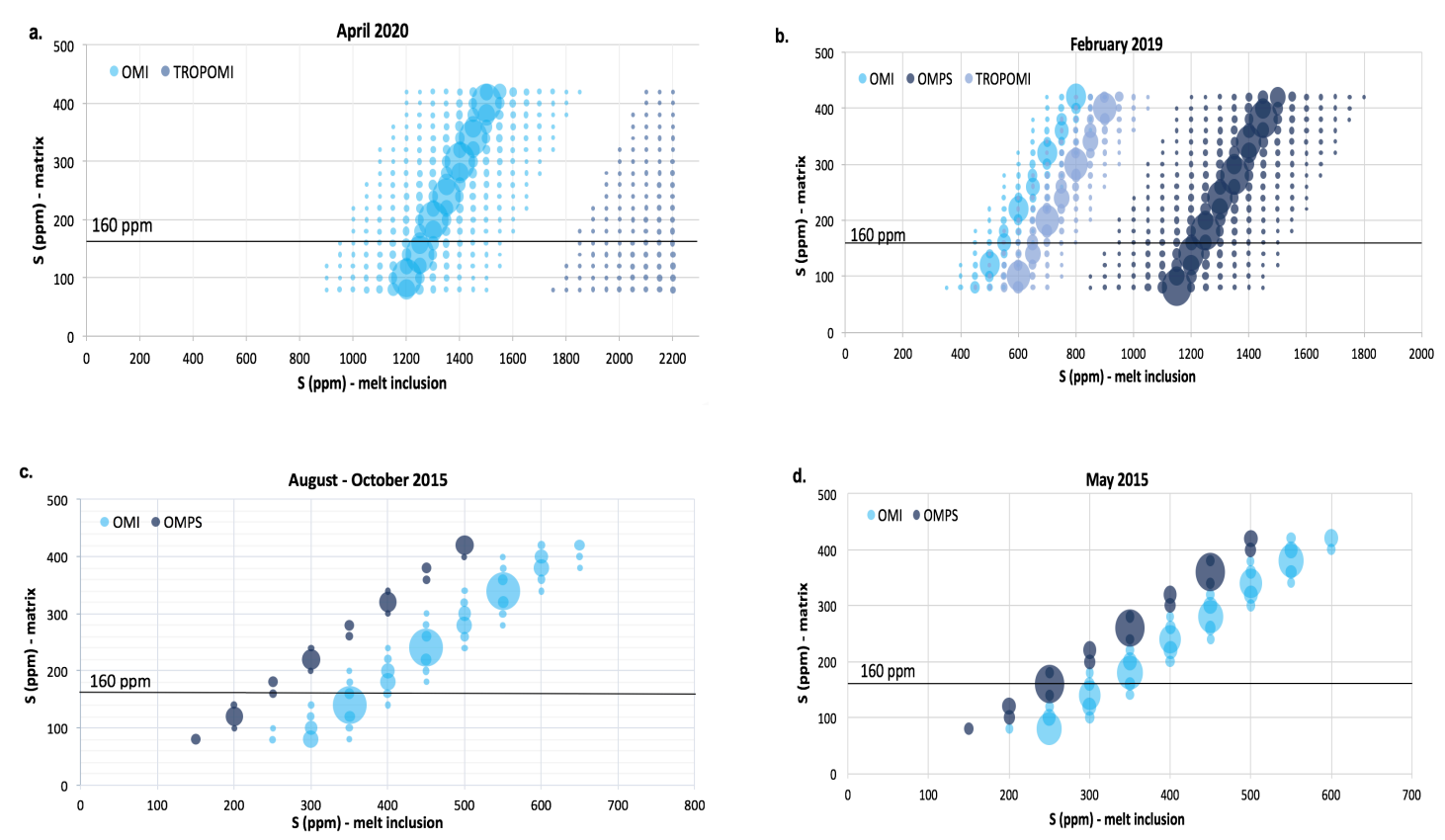

Figure 7: Estimation of sulfur content within melt inclusions using the petrological approach. The larger the symbol, the better the match with the total $\mathrm{SO}_{2}$ mass detected by the different UV sensors. According to the petrological analysis, the sulfur content in the matrix can be fixed at 160 ppm. This is represented by the black line. Note that no graph shows the April 2007 eruption, for which all $\mathrm{SO}_{2}$ masses estimated using the petrological method are lower than $270 \mathrm{kt}$ of $\mathrm{SO}_{2}$ detected by the OMI sensor.

\subsubsection{Temporal variation of sulfur content}

Figure 8 shows the daily magmatic sulfur contents estimated using satellitedetected $\mathrm{SO}_{2}$ masses and by fixing the sulfur content within the matrix and the lava. The April 2007 eruption is not represented as the values are greater than 30 $000 \mathrm{ppm} \mathrm{S}$, which is unrealistic. Note that this approach is dependent on the detection of $\mathrm{SO}_{2}$ by the UV sensors. Consequently, it is more difficult to build a time-series when a few days are missing, such as for the May 2015 eruption. The sensor may also partially miss the target, underestimating the emitted $\mathrm{SO}_{2}$ and adding an error to the estimated sulfur content within the melt inclusion. Nevertheless, in general, we obtained time-series that are in good agreement with each other (Figure 8).

Results are still lower than the value of $1050 \mathrm{ppm}$ S expected for the sealevel reservoir, which is in good agreement with the general view (Figure 7). For the February 2019 eruption, $c_{S}^{M I}$ is, on average, equal to $521 \pm 285$ ppm which is 
what we obtain from the OMI and TROPOMI instruments. However, OMPS data indicate a melt enriched in sulfur (Figure $7 b$ ), which could be explained by the visible peak at the end of the eruption (Figure 8). A similar observation can be made for the August-October 2015 eruption. Despite an almost constant $c_{S}^{M I}$ value of $283 \pm 191 \mathrm{ppm}$ (according to the OMI sensor), some peaks are observed, notably during the third and last phases of the eruption (October 16 - November 2 ), suggesting the involvement of an enriched melt.
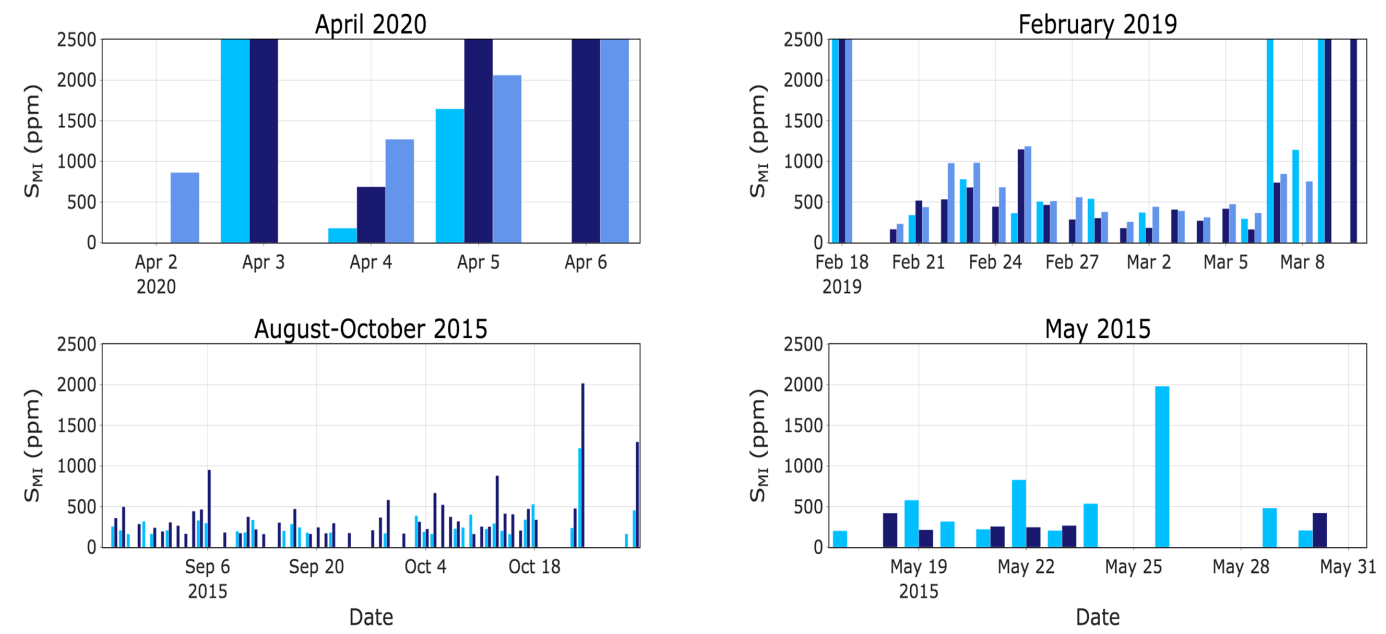

- OMI - OMPS - TROPOMI

Figure 8: Daily estimation of the sulfur content within melt inclusions at Piton de la Fournaise by fixing $c_{S}^{\text {matrix }}$ at 160 ppm, for eruptions in 2015-2020.

\subsection{Daily lava volume estimation from sulfur content}

We also re-arranged $\mathrm{Eq} \mathrm{(6)} \mathrm{to} \mathrm{calculate} \mathrm{the} \mathrm{expected} \mathrm{lava} \mathrm{volume} \mathrm{using} \mathrm{the}$ measured daily $\mathrm{SO}_{2}$ emissions and fixing $c_{S}^{\text {matrix }}(160 \mathrm{ppm})$ and $c_{S}^{M I}$. The first approach was to fix $c_{S}^{M I}$ at $1050 \mathrm{ppm}$ corresponding to the sea level magma reservoir. The second method used the $c_{S}^{M I}$ above (section 3.3.2), except that anomalous values were replaced by 1250 or $1600 \mathrm{ppm}$, as observed in the petrological analysis (Figure 6). The MIROVA lava volume was used as a reference. 


\subsubsection{Fixed sulfur content within the melt inclusions}

By fixing $c_{S}^{M I}$ at $1050 \mathrm{ppm}$, we expect higher lava output for the April 2007 and April 2020 eruptions (Figure 9a). The weather during the April 2020 eruption was cloudy, leading to underestimate lava volumes. This was also the case during the April 2007 eruption. However, for the two eruptions in 2015 (May 2015, AugOct 2015), we obtain lower lava volumes than those derived from MIROVA data (Figure 9a).

Generally OMI-derived total lava volumes are lower relative to field data, probably due to OMl's lower temporal resolution causing an underestimation of $\mathrm{SO}_{2}$ emissions (Table 5). OMPS data overestimate the lava volume for the April 2020 and February 2019 eruptions, but underestimates lava volumes for the eruptions in 2015. TROPOMl is in good agreement with the field bulk volume being 8.4 $\mathrm{Mm}^{3}$ and 6-10 $\mathrm{Mm}^{3}$, respectively (Table 5) for the April 2020 eruption suggesting that using an average of $1050 \mathrm{ppm}$ in the melt inclusion was a reasonable assumption. However, in February 2019, the field volume is significantly higher than our estimates $\left(14.5 \mathrm{Mm}^{3}\right.$ versus $6.3 \mathrm{Mm}^{3}$ ) (Table 5 and Figure 9). Following Figure 8, we expect values around $500 \mathrm{ppm}$ during the increase in TADR at the end of the eruption. Consequently, fixing a value at 1050 ppm may be unreasonable in this case.

\subsubsection{Variable sulfur content within melt inclusions}

As no realistic predictions for the sulfur content for the April 2007 eruption have been obtained, this method could not be applied for this event.

Results show similar daily lava volumes for April 2020 compared to the satellite-derived TADRs method (Figure 9a, Figure 9b). This suggests that the estimated pre-eruptive sulfur contents are realistic. For the February 2019 eruption, the cumulative volume derived using TROPOMI $\left(11.6 \mathrm{Mm}^{3}\right)$ is in good agreement with field data $\left(14.5 \mathrm{Mm}^{3}\right)$. The small difference in volumes could be related to a few missing days of intense activity (e.g., March 9-10) by TROPOMI. For the August-October 2015 eruption, OMPS provides a very similar cumulative 
volume to the field measurements ( $35.3 \mathrm{Mm}^{3}$ and $36.6 \mathrm{Mm}^{3}$, respectively). The total lava volume acquired based on $\mathrm{OMI} \mathrm{SO}_{2}$ emissions is lower $\left(24.5 \mathrm{Mm}^{3}\right)$. One may point out that the previous approach (fixed $c_{S}^{M I}$ ) gives much lower values (Table 5). Figure 7c and Figure 8, indicate a highly degassed melt during most of the eruption with fresh volatile-rich magma input at the end. Furthermore, at the end of the February 2019 and Aug-Oct 2015 eruptions, a peak in $\mathrm{SO}_{2}$ emissions is observed (Appendix 1). Hence, the variation in the pre-eruptive sulfur content estimated above (Figure 8) appears valid, and fixing $c_{S}^{M I}$ at $1050 \mathrm{ppm}$ may be an unrealistic assumption leading to underestimated lava volumes. The low estimated total lava volumes for the May 2015 eruption (Table 5) are likely due to missing days by the UV satellite sensors. As a consequence, no lava volume could have been calculated for those days.

Table 5: Cumulative volumes of erupted lava $\left(\mathrm{Mm}^{3}\right)$ estimated from: field measurements, MIROVA, and the petrological approach using OMI, OMPS and TROPOMI $\mathrm{SO}_{2}$ data. "OMI/OMPS/TROP $1050 "=$ sulfur content within melt inclusions fixed at 1050 ppm; "OMI/OMPS/TROP t" = pre-eruptive sulfur content varies over time.

\begin{tabular}{|c|c|c|c|c|c|c|c|c|}
\hline \multirow{2}{*}{ Eruption } & \multicolumn{8}{|c|}{ Cumulative Lava Volume $\left(\mathrm{Mm}^{3}\right)$} \\
\hline & Field & MIROVA & $\begin{array}{l}\text { OMI } \\
1050\end{array}$ & $\begin{array}{c}\text { OMPS } \\
1050\end{array}$ & $\begin{array}{c}\text { TROP } \\
1050\end{array}$ & $\underset{t}{\text { OMI }}$ & $\begin{array}{c}\text { OMPS } \\
\mathbf{t}\end{array}$ & $\underset{\mathbf{t}}{\text { TROP }}$ \\
\hline April 2020 & $6-10 *$ & $\begin{array}{c}2.9 \pm \\
1.0\end{array}$ & $\begin{array}{c}3.5 \pm \\
1.6\end{array}$ & $\begin{array}{c}19.4 \pm \\
8.8\end{array}$ & $\begin{array}{c}8.4 \pm \\
3.8\end{array}$ & $\begin{array}{c}3.1 \pm \\
2.2\end{array}$ & $\begin{array}{c}16.2 \pm \\
11.5\end{array}$ & $\begin{array}{c}6.3 \pm \\
4.5\end{array}$ \\
\hline February 2019 & $14.5^{* *}$ & $\begin{array}{c}13.6 \pm \\
4.8\end{array}$ & $\begin{array}{c}5.1 \pm \\
2.4\end{array}$ & $\begin{array}{c}22.4 \pm \\
10.8\end{array}$ & $\begin{array}{c}6.3 \pm \\
3.1\end{array}$ & $\begin{array}{c}9.2 \pm \\
6.1\end{array}$ & $\begin{array}{c}20.9 \pm \\
13.8\end{array}$ & $\begin{array}{l}11.6 \pm \\
7.6\end{array}$ \\
\hline Aug-Oct 2015 & $36.6^{* * *}$ & $\begin{array}{c}42.8 \pm \\
1.5\end{array}$ & $\begin{array}{c}3.9 \pm \\
1.8\end{array}$ & $\begin{array}{c}10.5 \pm \\
4.8\end{array}$ & - & $\begin{array}{c}24.5 \pm \\
17.2\end{array}$ & $\begin{array}{c}35.3 \pm \\
24.7\end{array}$ & - \\
\hline May 2015 & $5.7^{* * *}$ & $\begin{array}{c}6.0 \pm \\
2.1\end{array}$ & $\begin{array}{c}1.1 \pm \\
2.6\end{array}$ & $\begin{array}{c}0.6 \pm \\
0.3\end{array}$ & - & $\begin{array}{c}4.0 \pm \\
2.5\end{array}$ & $\begin{array}{c}3.5 \pm \\
2.2\end{array}$ & - \\
\hline April 2007 & $185^{* * *}$ & $\begin{array}{c}126.1 \pm \\
63.0\end{array}$ & $\begin{array}{c}369.8 \pm \\
178.9\end{array}$ & - & - & - & - & - \\
\hline
\end{tabular}

* (Peltier et al., 2020), Bulk Volume, ${ }^{* *}$ Preliminary results - N. Villeneuve, ${ }^{* * *}$ (Derrien, 2019), Volume DRE 
By estimating the lava volume with the petrological approach and by fixing $c_{S}^{M I}$ at $1050 \mathrm{ppm}$, we either overestimate lava volume (e.g., April 2020, February 2019, and April 2007) or underestimate lava volume (2015) relative to field data. For the April 2020 eruption, the field measurement corresponds to the bulk (not DRE) volume. This likely explains the higher values estimated with $\mathrm{SO}_{2}$ mass detected by the OMPS and TROPOMI sensors.

The UV sensors missed a few days of the May 2015 eruption, leading to underestimated volumes. However, by assuming a variable sulfur content within the melt inclusions, we acquired good results for both 2015 eruptions. This may suggest that a $c_{S}^{M I}$ of $1050 \mathrm{ppm}$ may not be realistic for these eruptions.

It is also important to point out that the results obtained with this method for the April 2020 eruption are more accurate than those derived from MODIS image processing (MIROVA; Table 5). Bad weather during the eruption made it difficult to detect thermal anomalies, leading to underestimated TADR. In such cases, the petrological approach appears to be a good alternative method for lava volume estimation. 
a. Cumulative Volume by fixing $S_{M I}=$ $1050 \mathrm{ppm}$

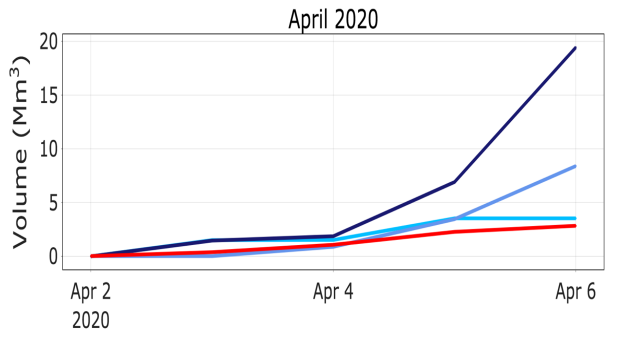

February 2019

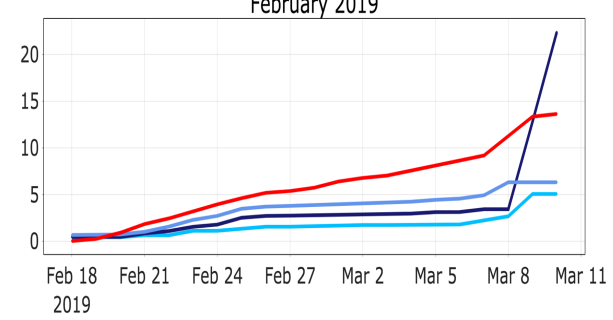

August-October 2015

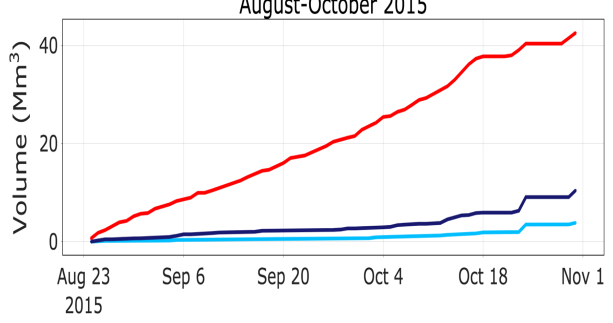

May 2015
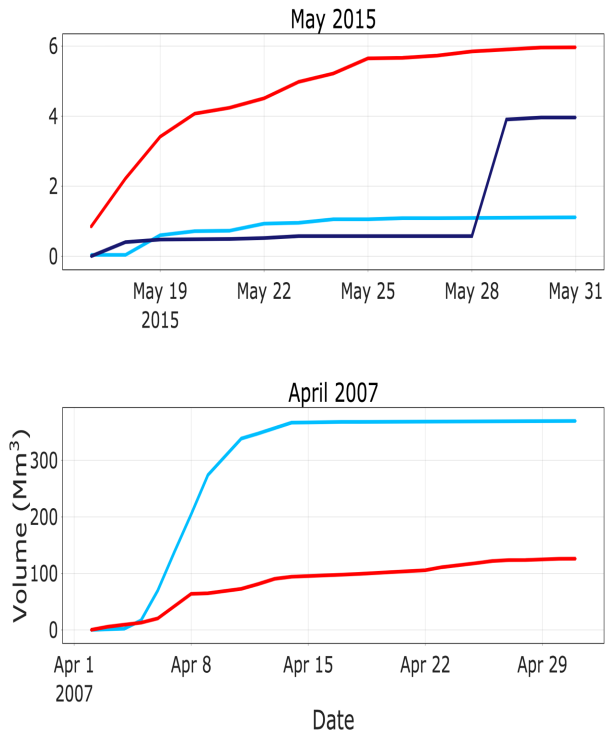

\section{b. Cumulative Volume by varying $S_{M}$}

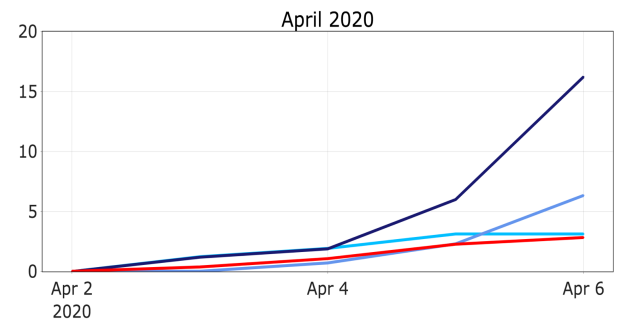

February 2019

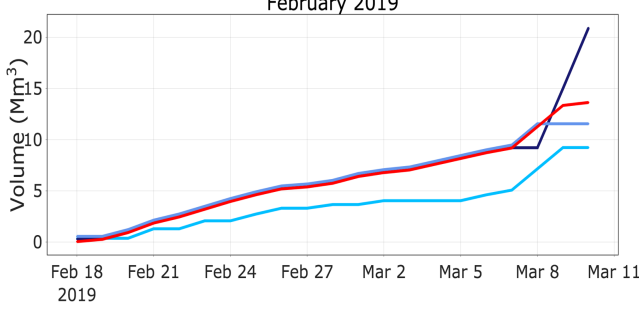

August-October 2015

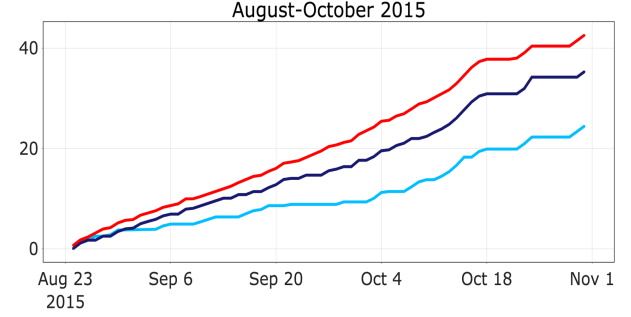

May 2015

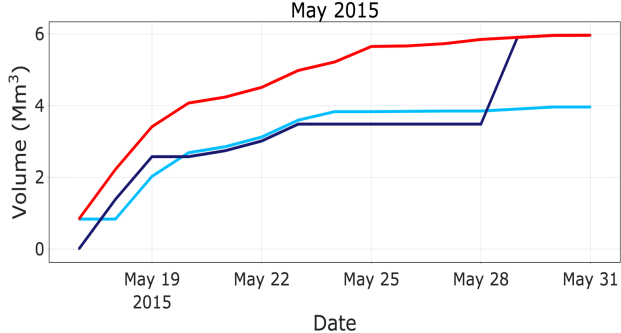

-OMI-OMPS-TROPOMI-MIROVA

Figure 9: (a) Cumulative lava volume estimated by fixing the sulfur content within melt inclusions at $1050 \mathrm{ppm}$. (b) Cumulative lava volume estimated using sulfur contents calculated from the MIROVA lava volume. Hence, note the relationship between them. Anomalous sulfur contents (greater than 2000 ppm) have been replaced with 1250 or 1600 ppm. As no estimated sulfur content within the melt inclusion was realistic for the April 2007 eruption, the second approach could not be applied. 


\section{Discussion}

The objectives of this project is to reconcile the two MODIS systems (MODVOLC and MIROVA) and the UV sensors for TADR and $\mathrm{SO}_{2}$ flux, respectively. The aim is to define the optimum approach for tracking eruptions under different eruptive, and meteorological, conditions. The analysis of a suite of eruptions at different locations and with by different trends also yields insight into the characteristics of the magma reservoir(s) supplying these events (cf. Coppola et al., 2017). This is, thus, our second objective.

\section{1. $\mathrm{SO}_{2}$ flux measurements from space and the NOVAC network}

The statistical comparison between $\mathrm{SO}_{2}$ mass estimation from OMI/OMPS/TROPOMI and NOVAC measurements illustrates the challenges of comparing satellite masses with ground-based fluxes. The wind direction for the ground-based fluxes, and plume altitude for the satellites, adds significant uncertainty to the values. Nevertheless, we find good agreement for the eruptions located within the field of view of the NOVAC network (Figure 1c). This indicates that for eruptions where the vents are not visible from a NOVAC station, the NOVAC measurements are not optimal, and underestimate the flux if it is visible at-all. Adjusting the location of the NOVAC stations and/or expanding the network would be one solution. Based on our results, moving one or two of the three stations slightly to the East adding a fourth station on the East flank of Piton de la Fournaise would provide better coverage for future eruption vents in this area.

\subsection{Discharge of the magmatic system}

\subsubsection{April 2007}

The April 2007 eruption was characterized by particularly high TADRs (Appendix 2). Assuming that the lava flow field volume estimated at $185 \mathrm{Mm}^{3}$ by Derrien, (2019) is correct, then we see from Table 3 that the volume estimates based on MODIS thermal anomalies generally underestimate (by $32-73 \%$ ) the actual volume. As the eruption was particularly intense (peak TADR of $100 \mathrm{~m}^{3} \mathrm{~s}^{-}$ 
${ }^{1}$ ), MODIS sensor saturation likely resulted in under-estimated values, meaning that Table 3 values are "minimum-bounds". This is supported by hot spot temperatures of up to $780^{\circ} \mathrm{C}$ (Staudacher et al., 2009) and the pixel saturation assessment of Figure 2. Indeed, $1 \%$ coverage by surfaces at $780{ }^{\circ} \mathrm{C}$ in a $1 \mathrm{~km}^{2}$ pixel would have been sufficient to saturate Band 21, equivalent to a $9800 \mathrm{~m}^{2}$ hot spot. Moreover, some of the lava flows were tube-fed and entered the ocean (Staudacher et al., 2009). Consequently, part of the thermal emissions is missing. To counter this effect, the TADR estimations have been increased by $30 \%$, however this still results in an underestimate. To square with the field-based measurements the results of Table 3 shows that the adjustment factor needs to be $73 \%$. Using the $\mathrm{SO}_{2}$ emissions we found a larger lava volume (369.8 \pm 178.9 $\mathrm{Mm}^{3}$ ) than that measured in the field. This paroxysmal eruption released a large amount of $\mathrm{SO}_{2}$ due to the fast ascent of a very deep magma from the mantle depth (Staudacher et al., 2009), leading to overestimate lava volume using the petrological approach. Hence, due to saturation and excess $S$ problems, for paroxysmal eruptions, the best way to determine the amount of lava erupted comes from field measurements.

$\mathrm{SO}_{2}$ emissions peaked during the collapse of the Dolomieu crater on April 6 before a rapid decline after April 8 (Appendix 1). This sulfur excess (269 kt during the most intense phase) in respect to the volume of lava erupted can be linked to a deep magma input that would have pressurized the shallow reservoir and lead to this type of intense activity at Piton de la Fournaise, as suggested by Di Muro et al., (2014). According to Walker, (1988) the collapses being preceded by an increased in TADR suggest an enhancement in the drainage of the shallow system leading to a passive caldera formation. This behavior is observed at other basaltic shields that experience high effusion rate and/or voluminous eruptions (e.g., Kilauea (Hawaii) - (Tepp et al., 2020)). 


\subsubsection{May 2015}

This eruption started on May 17 and was characterized by high initial TADR $\left(30 \mathrm{~m}^{3} \mathrm{~s}^{-1}\right.$ ) followed by logaritmic decay to $14 \mathrm{~m}^{3} \mathrm{~s}^{-1}$ (Figure $4 \mathrm{~b}$ ). The same trend is evident in the $\mathrm{SO}_{2}$ emissions (Appendix 1 and Appendix 2), and is typically of tapping of a pressurized source (Wadge, 1981). According to the field measurements, the erupted products amount to $5.7 \mathrm{Mm}^{3}$. The total lava volume derived from MODIS data analysis is in good agreement except for the MODVOLC data, where we obtained a lava volume of $9.0 \pm 2.7 \mathrm{Mm}^{3}$. Despite MODVOLC data gaps, this system overestimates the total lava erupted, mostly due to the bow-tie effect (Appendix 3). At high scan angles, the earth curvature cannot be neglected by the MODIS instrument leading to scan-to-scan overlap so that hot spot radiances are counted twice (Coppola et al., 2010). Instead, the total volume estimated using a fixed $c_{S}^{M I}$ of $1050 \mathrm{ppm}$ underestimates the lava emitted giving $0.85 \mathrm{Mm}^{3}$. However, using a $c_{S}^{M I}$ of $430 \pm 157 \mathrm{ppm}$ provides a better estimation (Figure 9b). Note that the underestimation in both cases may also be an artifact of the low temporal resolution of the UV sensors leading to an unrepresentative timeseries of $\mathrm{SO}_{2}$ emissions. According to the petrological analysis, the pre-eruptive sulfur content of $430 \pm 157 \mathrm{ppm}$ may be too low (Figure 6). Although pre-eruptive sulfur contents of 500 ppm are known, such cases are rare (Di Muro et al., 2015). We should expect a value of around $1050 \mathrm{ppm}$.

It is also important to note that the May 2015 eruption emitted a more evolved magma than usual (Sundermeyer et al., 2019). In mid-April 2015, deep seismicity and an increase in $\mathrm{CO}_{2}$ discharge were recorded, suggesting the ascent of new mafic magma from depth into the shallow reservoir at $0.5-1.5 \mathrm{~km}$ below sea level (Peltier et al., 2016). Consequently, between mid-April and mid-May, magma differentiation processes may have occurred in the shallow reservoir. No apparent mafic input is recorded in the sulfur content variation in Figure 8, suggesting that magma supplying the May 2015 eruption came from the upper part of the shallow reservoir. This was extruded due to the arrival of new magma at the chamber base. That could explain the low and nearly constant sulfur content estimated with the 
petrological approach. This is another common process at basaltic shields (Thornber, 2003).

\subsubsection{August-October 2015}

The August-October 2015 eruption can be divided into three phases on the basis of TADR (Figure 4a). The first phase is marked by a high TADR (peak of 50 $\mathrm{m}^{3} \mathrm{~s}^{-1}$ ) and is followed by a decline to a nearly constant TADR at $5 \mathrm{~m}^{3} \mathrm{~s}^{-1}$ in phase 2. Three short-lived pulses, each about two days long, characterize the last phase. The lava volume erupted during this last 6-day long phase represents almost 50 $\%\left(\sim 11 \mathrm{Mm}^{3}\right)$ of the total emitted from August 24 to October $17\left(\sim 32 \mathrm{Mm}^{3}\right)$. By integrating the TADR through time, the MIROVA and Manual methods yield equivalent total volumes. However, the MODVOLC system again overestimates the volume by $\sim 40 \mathrm{Mm}^{3}$ (Table 3). As with the May 2015 eruption, we obtain an underestimation by 33 to $26 \mathrm{Mm}^{3}$ of the total lava volume if we fix the pre-eruptive sulfur content at $1050 \mathrm{ppm}$ (Table 5). Depending on the UV sensor, we obtained $3.9 \pm 1.8 \mathrm{Mm}^{3}$ (OMI) and $10.5 \pm 4.8 \mathrm{Mm}^{3}$ (OMPS) when we expect a total lava volume of $36.6 \mathrm{Mm}^{3}$ according to field measurements. Using the pre-eruptive sulfur content from the petrological approach ( $\pm 466 \mathrm{ppm}$ ), volume estimations are better (OMPS: $35.3 \pm 24.7 \mathrm{Mm}^{3}$ ). The OMI dataset slightly underestimates the lava emitted $\left(24.5 \pm 17.2 \mathrm{Mm}^{3}\right)$ likely due to data gaps during the last phase of the eruption.

Figure 8 reveals a nearly constant $c_{S}^{M I}$ of $200-700 \mathrm{ppm}$ before an increase to 2000 ppm during the last phase. This may suggest an evolution from a degassed melt during the two first phases to a mafic gas-rich melt during the last stage of the event. This is consistent with Sundermeyer et al. (2019) who modelled diffusion times within olivine crystals. Sundermeyer et al. (2019) noted a progressive increase of the $\mathrm{MgO}$ magma content during the third phase, which was accompanied by increased $\mathrm{CO}_{2}$ in summit fumarole emissions (Coppola et al., 2017). In addition, the erupted products indicate that recharging magmas 
dominated evolved melts during the final stage, probably because the shallow reservoir had been almost emptied by the three previous eruptions in 2015 .

\subsubsection{February 2019}

The trends in TADR and $\mathrm{SO}_{2}$ emissions (Appendix 2) show this eruption to be characterized by a terminal burst. This was related to the opening of a new EW trending fissure on March 7, 17 days after the onset of the eruption and 3 days before the end. TADR was estimated at $\sim 10 \mathrm{~m}^{3} \mathrm{~s}^{-1}$ before this event increasing to 19-37 $\mathrm{m}^{3} \mathrm{~s}^{-1}$ on March 9-10 (Appendix 2a). TROPOMI missed the end of the eruption. However, a peak is observable with the two other instruments: OMI (4.9 $\mathrm{kt}$ ) and OMPS (19.2 kt) on March 9, coinciding with the TADR increase (Appendix 1). According to the field data, the total lava volume emitted during this event was around $14.5 \mathrm{Mm}^{3}$. The MIROVA dataset provides a similar value (Table 3). Despite the absence of hot spots after March 3, missing the intense surface activity at the end of the eruption, MODVOLC also gives a reasonable cumulative lava volume estimate (11.2 $\mathrm{Mm}^{3}$ ) probably due to the bow tie effect (Coppola et al., 2010). On the other hand, the estimate from manual MODIS processing is lower $\left(9.5 \mathrm{Mm}^{3}\right)$. This can only be due to an underestimation of the TADR, so that the conversion coefficients of Equation 5 need to be adjusted for this style of activity.

Figure 9 shows two different trends in cumulative volume acquired from the petrological approach. Using a fixed $c_{S}^{M I}$, we observe lower lava volume estimations. However, by varying the pre-eruptive sulfur content, we obtain cumulative lava volumes closer to the MIROVA and field-based measurements. This suggests that a relatively constant $c_{S}^{M I}$ of $528 \pm 284 \mathrm{ppm}$ during the eruption is reasonable. This value would be consistent with a differentiated melt coming from the shallow reservoir. However, we observe an increase in apparent $c_{S}^{M I}$ at the end of the eruption corresponding to the increase in TADR and $\mathrm{SO}_{2}$ emissions. This may suggest that the fissure eruption was fed by a volatile-rich, less evolved melt: formation of new dyke or emptying of the shallow reservoir allowing fresh magma to erupt as in the third phase of the August-October 2015 eruption. 


\subsubsection{April 2020}

The 2-6 April 2020 eruption occurred, close to the site of the February 2019 eruption. Weak ground deformation and a low number of seismic events suggest that the pathway for magma ascent was already open following the 2019 eruption (Peltier et al., 2020). On April 4, seismicity increased until April 6, when the eruption stopped abruptly. During this period, large quantities of Pele's hair were emitted (Peltier et al., 2020), indicating a particularly explosive event for Piton de la Fournaise (with high fountains) and, thus, strong volcanic degassing. This is supported by the total mass of $\mathrm{SO}_{2}$ detected during April 4-6 by TROPOMI, OMPS, and OMI (17.32 kt, $36.67 \mathrm{kt}$ and $4.12 \mathrm{kt}$, respectively). An OMI data gap on April 6 during the highest $\mathrm{SO}_{2}$ emissions (Appendix 1 ) explains the low OMI value. According to Peltier et al. (2020), the bulk lava volume ranges from 6-10 $\mathrm{Mm}^{3}$. MODIS image processing yields a bulk volume of $2-4 \mathrm{Mm}^{3}$ with a $\sim 35 \%$ error (Table 3). Given this is a DRE volume and that of Peltier et al. (2020) is bulk, this suggests an overall vesicularity of $20-40 \%$, which is typical for basaltic lava flows (Harris and Rowland, 2015). Cloud cover significantly compromised the availability of usable (cloud-free) images, indicating that caution should be used when using satellite-derived data which should always be cloud-screened to check to cloudcover induced trends and drop-outs (cf. Harris and Thornber, 1999).

On the other hand, the lava volume estimated using the petrological approach gives higher estimations (Table 5). The high bias (nearly $20 \mathrm{Mm}^{3}$ ) in the OMPS data may be due to lower spatial resolution $\left(50 \times 50 \mathrm{~km}^{2}\right)$, resulting in an overestimation of the $\mathrm{SO}_{2}$ detected from space. In addition, the results indicate that fixing $c_{S}^{M I}$ at $1050 \mathrm{ppm}$ is a reasonable assumption for this eruption. According to the petrological data (Figure 6), a sulfur content of $1050 \mathrm{ppm}$ represents, on average, the sea level magma reservoir of Piton de la Fournaise suggesting that the April 2020 eruption was supplied by this shallow reservoir. However, Figure 8 also shows an increase in pre-eruptive sulfur content, probably resulting from deeper mafic inputs. The continuous increase in soil $\mathrm{CO}_{2}$ fluxes supports the idea 
of a deep magma influx into the sea level reservoir (Peltier et al., 2020) after initial emptying. 


\section{Conclusion}

Multiple datasets have been acquired for five eruptions at Piton de la Fournaise, La Réunion. Analysis of the temporal evolution of TADR, combined with the associated $\mathrm{SO}_{2}$ emissions and sulfur content within melt inclusions, reveals that Piton de la Fournaise eruptions may follow several distinct trends, where we have here defined three: paroxysmal eruption, classic exponential decaying and terminal burst.

Manual processing of MODIS data validates the efficiency of hot spot detection and TADR-derivation by the MIROVA system during the effusive eruptions at Piton de la Fournaise, meaning that the conversion coefficient in Equation 5 is valid. In contrast, we find that the MODVOLC system often overestimates TADR and, also, the total erupted volume. This is unexpected given that the MODVOLC system often fails to detect hot spots, which should lead to underestimation of TADRs and lava volumes. This is particularly apparent for the April 2020 eruption: despite having only three measurements (compared to 11 for MIROVA and manual processing), MODVOLC provides the highest lava volume estimates, likely due to double counting resulting from the bow tie effect (Appendix 2). Nevertheless, lava erupted during bad weather is significantly underestimated by all the approaches compared to the field measurements. Underestimation of lava volume also occurred during the paroxysmal eruption in April 2007 due to widespread saturation of the MODIS TIR channels (Table 3 ).

Using a petrological method and the erupted lava masses obtained from MODIS data, we have derived a time-series of apparent sulfur content within melt inclusions for each of the five eruptions considered. Some results show lower values than expected from petrological analysis. This could be explained by the involvement of largely degassed magma in the eruptions. On the other hand, increased TADR and $\mathrm{SO}_{2}$ emissions at the end of the February 2019 and AugustOctober 2015 eruptions (terminal bursts) suggest an increase in pre-eruptive sulfur content. This may indicate replenishment of the shallow magma reservoir by deeper, volatile-rich mafic inputs. Also, total lava volumes estimated using the $\mathrm{SO}_{2}$ 
emissions detected by OMI, OMPS and TROPOMI are in good agreement with ground-truth. Hence, using the $\mathrm{SO}_{2}$ emissions and pre-eruptive sulfur contents could be a viable alternative to estimate lava volumes during bad weather, when the satellite-derived TADRs may be compromised. However, we also recognize that during very bad weather conditions when both thermal anomalies and $\mathrm{SO}_{2}$ plumes are partially or wholly undetectable, neither satellite-based technique (IR or UV) may provide accurate results.

The analysis of multiple datasets for a sequence of effusive eruptions from a single magmatic system provides insight into eruptive processes at basaltic volcanoes. We expect, in general, a strong initial peak in TADR accompanied by a peak in $\mathrm{SO}_{2}$ emissions before an exponential decrease for the classic "waxingwaning" trend for effusive eruptions defined by Wadge, 1981. However, for two eruptions at Piton de la Fournaise, we observe a waxing trend at the end (terminal burst). For these cases, we show that an increase in magmatic sulfur content correlates with an intense in TADR and an enrichment in $\mathrm{CO}_{2}$ within the summit fumaroles. Hence, we propose that after (almost) complete emptying of the shallow magma reservoir, the recharging magma dominates over pre-existing degassed magma at the end of the eruption. Alternatively, once the evolved magma occupying the upper part of the shallow reservoir is discharged, less evolved magma in the central or lower part of the reservoir is then erupted. A recharching magma, in both cases, is probably the cause of pressurization of the plumbing system leading to intense TADR in the terminal phase.

Based on this work, we suggest three improvements to aid with the remote sensing based the monitoring of Piton de la Fournaise and some potential areas of future research:

- According to our preliminary results, we suggest moving one or two of the three NOVAC network stations slightly to the East or the addition of another station on the East flank of Piton de la Fournaise to allow efficient surveys of future vents in this area. Also, a more extended comparison 
between the satellite $\mathrm{SO}_{2}$ masses and the ground-based $\mathrm{SO}_{2}$ fluxes could allow validation of one or both measurements.

- This study demonstrates that the MODVOLC system failed to detect a few hot spots despite a Normalized Thermal Index (NTI) greater than the -0.80 threshold, this being that used by this system (Wright, 2016). Furthermore, it appears that MODVOLC overestimates the TADR and hence the total lava volume. Consequently, MODVOLC data should be used with caution when used for TADR conversion. However, MIROVA appears well calibrated to produce reliable TADR for PdF.

- Finally, we also suggest further analysis of ground deformation and seismicity datasets or use of Bayesian inversion methods to model the source of deformation during magma migration at Piton de la Fournaise (cf. Beauducel et al., 2020). These data could test our hypothesis of deeper mafic inputs that could be the origin of the increase in sulfur content suggested by the temporal variations in $\mathrm{SO}_{2}$ emissions. 


\section{References}

Bachelery, P. (1981). Le Piton de la Fournaise, lle de la Réunion: Étude volcanologique, structurale et pétrologique.

Barsi, J. A., Barker, J. L., \& Schott, J. R. (2003). An Atmospheric Correction Parameter Calculator for a single thermal band earth-sensing instrument. IGARSS 2003. 2003 IEEE International Geoscience and Remote Sensing Symposium. Proceedings (IEEE Cat. No.03CH37477), 5, 3014-3016 vol.5. https://doi.org/10.1109/IGARSS.2003.1294665

Beauducel, F., Peltier, A., Villié, A., \& Suryanto, W. (2020). Mechanical Imaging of a Volcano Plumbing System From GNSS Unsupervised Modeling. Geophysical Research Letters, 47(17), e2020GL089419. https://doi.org/10.1029/2020GL089419

Bhugwant, C., Siéja, B., Bessafi, M., Staudacher, T., \& Ecormier, J. (2009). Atmospheric sulfur dioxide measurements during the 2005 and 2007 eruptions of the Piton de La Fournaise volcano: Implications for human health and environmental changes. Journal of Volcanology and Geothermal Research, 184(1), 208-224. https://doi.org/10.1016/j.jvolgeores.2009.04.012

Carn, S. A., Yang, K., Prata, A. J., \& Krotkov, N. A. (2015). Extending the long-term record of volcanic $\mathrm{SO}_{2}$ emissions with the Ozone Mapping and Profiler Suite nadir mapper: OMPS volcanic SO2 measurements. Geophysical Research Letters, 42(3), 925-932. https://doi.org/10.1002/2014GL062437

Chevallier, L., \& Bachelery, P. (1981). Evolution structurale du volcan actif du Piton de la Fournaise, lle de la Réunion-Océan indien occidental. Bulletin Volcanologique, 44(4), 723-741. https://doi.org/10.1007/BF02597094

Coppola, D., Di Muro, A., Peltier, A., Villeneuve, N., Ferrazzini, V., Favalli, M., Bachèlery, P., Gurioli, L., Harris, A. J. L., Moune, S., Vlastélic, I., Galle, B., Arellano, S., \& Aiuppa, A. (2017). Shallow system rejuvenation and magma discharge trends at Piton de la Fournaise volcano (La Réunion Island). Earth and Planetary Science Letters, 463, 13-24. https://doi.org/10.1016/j.epsl.2017.01.024

Coppola, D., James, M. R., Staudacher, T., \& Cigolini, C. (2010). A comparison of field- and satellite-derived thermal flux at Piton de la Fournaise: Implications for the calculation of lava discharge rate. Bulletin of Volcanology, 72(3), 341-356. https://doi.org/10.1007/s00445-009-0320-8

Coppola, D., Laiolo, M., Cigolini, C., Donne, D. D., \& Ripepe, M. (2016). Enhanced volcanic hot-spot detection using MODIS IR data: Results from the MIROVA system. Geological Society, London, Special Publications, 426(1), 181205. https://doi.org/10.1144/SP426.5

Coppola, D., Laiolo, M., Piscopo, D., \& Cigolini, C. (2013). Rheological control on the radiant density of active lava flows and domes. Journal of Volcanology and Geothermal Research, 249, 39-48. https://doi.org/10.1016/j.jvolgeores.2012.09.005

Coppola, D., Piscopo, D., Staudacher, T., \& Cigolini, C. (2009). Lava discharge rate and effusive pattern at Piton de la Fournaise from MODIS data. Journal of Volcanology and Geothermal Research, 184(1), 174-192. https://doi.org/10.1016/j.jvolgeores.2008.11.031 
Deniel, C., Kieffer, G., \& Lecointre, J. (1992). New 230Th-238U and 14C age determinations from Piton des Neiges volcano, Reunion-A revised chronology for the Differentiated Series. Journal of Volcanology and Geothermal Research, 51(3), 253-267. https://doi.org/10.1016/0377-0273(92)90126-X

Derrien, A. (2019). Apports des techniques photogrammétriques à l'étude du dynamisme des structures volcaniques du piton de la Fournaise [PhD Thesis]. http://www.theses.fr/2019UNIP7084/document

Di Muro, A., Metrich, N., Vergani, D., Rosi, M., Armienti, P., Fougeroux, T., Deloule, E., Arienzo, I., \& Civetta, L. (2014). The Shallow Plumbing System of Piton de la Fournaise Volcano (La Reunion Island, Indian Ocean) Revealed by the Major 2007 Caldera-Forming Eruption. Journal of Petrology, 55(7), 1287-1315. https://doi.org/10.1093/petrology/egu025

Di Muro, Andrea, Métrich, N., Allard, P., Aiuppa, A., Burton, M., Galle, B., \& Staudacher, T. (2016). Magma Degassing at Piton de la Fournaise Volcano. In P. Bachelery, J.-F. Lenat, A. Di Muro, \& L. Michon (Eds.), Active Volcanoes of the Southwest Indian Ocean (pp. 203-222). Springer Berlin Heidelberg. https://doi.org/10.1007/978-3-642-31395-0_12

Duncan, R. A. (1981). Hotspots in the Southern Oceans-An absolute frame of reference for motion of the Gondwana continents. Tectonophysics, 74(1), 29-42. https://doi.org/10.1016/0040-1951(81)90126-8

Flynn, L., Long, C., Wu, X., Evans, R., Beck, C. T., Petropavlovskikh, I., McConville, G., Yu, W., Zhang, Z., Niu, J., Beach, E., Hao, Y., Pan, C., Sen, B., Novicki, M., Zhou, S., \& Seftor, C. (2014). Performance of the Ozone Mapping and Profiler Suite (OMPS) products. Journal of Geophysical Research: Atmospheres, 119(10), 6181-6195. https://doi.org/10.1002/2013JD020467

Gailler, L.-S., \& Lénat, J.-F. (2010). Three-dimensional structure of the submarine flanks of La Réunion inferred from geophysical data. Journal of Geophysical Research: Solid Earth, 115(B12). https://doi.org/10.1029/2009JB007193

Gailler, L.-S., Lénat, J.-F., Lambert, M., Levieux, G., Villeneuve, N., \& Froger, J.-L. (2009). Gravity structure of Piton de la Fournaise volcano and inferred mass transfer during the 2007 crisis. Journal of Volcanology and Geothermal Research, 184(1), 31-48. https://doi.org/10.1016/j.jvolgeores.2009.01.024

Galle, B., Johansson, M., Rivera, C., Zhang, Y., Kihlman, M., Kern, C., Lehmann, T., Platt, U., Arellano, S., \& Hidalgo, S. (2010). Network for Observation of Volcanic and Atmospheric Change (NOVAC)—A global network for volcanic gas monitoring: Network layout and instrument description. Journal of Geophysical Research, 115(D5), D05304. https://doi.org/10.1029/2009JD011823

Gillot, P.-Y., \& Nativel, P. (1989). Eruptive history of the Piton de la Fournaise volcano, Reunion Island, Indian Ocean. Journal of Volcanology and Geothermal Research, 36(1), 53-65. https://doi.org/10.1016/03770273(89)90005-X 
Gouhier, M., \& Coppola, D. (2011). Satellite-based evidence for a large hydrothermal system at Piton de la Fournaise volcano (Reunion Island): HYDROTHERMAL SYSTEM AND SO 2 EMISSIONS. Geophysical Research Letters, 38(2), n/a-n/a. https://doi.org/10.1029/2010GL046183

Harris, A. (2013a). Detection capabilities of thermal sensors-Electronic Supplement 1. In Thermal Remote Sensing of Active Volcanoes A User's Manual (pp. 1-57).

Cambridge. https://www.cambridge.org/files/3313/6698/1587/Harris_electronic_supplement_ 1.pdf

Manual.

Harris, A. (2013b). Thermal Remote Sensing of Active Volcanoes: A User's https://doi.org/10.1017/CBO9781139029346

Harris, A. J. L., Pilger, E., Flynn, L. P., Garbeil, H., Mouginis-Mark, P. J., Kauahikaua, J., \& Thornber, C. (2001). Automated, high temporal resolution, thermal analysis of Kilauea volcano, Hawai'i, using GOES satellite data. International Journal of Remote Sensing, 22(6), 945-967. https://doi.org/10.1080/014311601300074487

Harris, A. J. L., \& Thornber, C. R. (1999). Complex effusive events at Kìlauea as documented by the GOES satellite and remote video cameras. Bulletin of Volcanology, 61(6), 382-395. https://doi.org/10.1007/s004450050280

Harris, Andrew J. L., \& Baloga, S. M. (2009). Lava discharge rates from satellite-measured heat flux. Geophysical Research Letters, 36(19), L19302. https://doi.org/10.1029/2009GL039717

Harris, Andrew J. L., Flynn, L. P., Keszthelyi, L., Mouginis-Mark, P. J., Rowland, S. K., \& Resing, J. A. (1998). Calculation of lava effusion rates from Landsat TM data. Bulletin of Volcanology, 60(1), 52-71. https://doi.org/10.1007/s004450050216

Harris, Andrew J. L., \& Ripepe, M. (2007). Regional earthquake as a trigger for enhanced volcanic activity: Evidence from MODIS thermal data. Geophysical Research Letters, 34(2), L02304. https://doi.org/10.1029/2006GL028251

Harris, Andrew J.L., \& Rowland, S. K. (2015). Lava Flows and Rheology. In The Encyclopedia of Volcanoes (pp. 321-342). Elsevier. https://doi.org/10.1016/B978-0-12-385938-9.00017-1

Harris, Andrew J.L., \& Stevenson, D. S. (1997). Thermal observations of degassing open conduits and fumaroles at Stromboli and Vulcano using remotely sensed data. Journal of Volcanology and Geothermal Research, 76(3-4), 175198. https://doi.org/10.1016/S0377-0273(96)00097-2

Hibert, C., Mangeney, A., Polacci, M., Muro, A. D., Vergniolle, S., Ferrazzini, V., Peltier, A., Taisne, B., Burton, M., Dewez, T., Grandjean, G., Dupont, A., Staudacher, T., Brenguier, F., Kowalski, P., Boissier, P., Catherine, P., \& Lauret, F. (2015). Toward continuous quantification of lava extrusion rate: Results from the multidisciplinary analysis of the 2 January 2010 eruption of Piton de la 
Fournaise volcano, La Réunion: JANUARY 2010 ERUPTION AT PDf. Journal of Geophysical Research: Solid Earth, 120(5), 3026-3047. https://doi.org/10.1002/2014JB011769

Hook, S. J., Myers, J. J., Thome, K. J., Fitzgerald, M., \& Kahle, A. B. (2001). The MODIS/ASTER airborne simulator (MASTER)—A new instrument for earth science studies. Remote Sensing of Environment, 76(1), 93-102. https://doi.org/10.1016/S0034-4257(00)00195-4

Levelt, P. F., Oord, G. H. J. van den, Dobber, M. R., Malkki, A., Huib Visser, Johan de Vries, Stammes, P., Lundell, J. O. V., \& Saari, H. (2006). The ozone monitoring instrument. IEEE Transactions on Geoscience and Remote Sensing, 44(5), 1093-1101. https://doi.org/10.1109/TGRS.2006.872333

Mahoney, J. J., Duncan, R. A., Khan, W., Gnos, E., \& McCormick, G. R. (2002). Cretaceous volcanic rocks of the South Tethyan suture zone, Pakistan: Implications for the Réunion hotspot and Deccan Traps. Earth and Planetary Science Letters, 203(1), 295-310. https://doi.org/10.1016/S0012-821X(02)008403

Michon, L., Di Muro, A., Villeneuve, N., Saint-Marc, C., Fadda, P., \& Manta, F. (2013). Explosive activity of the summit cone of Piton de la Fournaise volcano (La Réunion island): A historical and geological review. Journal of Volcanology and Geothermal

Research, 264, 117-133. https://doi.org/10.1016/j.jvolgeores.2013.06.012

Michon, L., Staudacher, T., Ferrazzini, V., Bachèlery, P., \& Marti, J. (2007). April 2007 collapse of Piton de la Fournaise: A new example of caldera formation. Geophysical Research Letters, 34(21), L21301. https://doi.org/10.1029/2007GL031248

Monthly bulletin of the Piton de la Fournaise Volcanological Observatory. (2019). OVPF - IPGP.

Morgan, W. [Jason. (1983). Hotspot tracks and the early rifting of the Atlantic. Tectonophysics, 94(1), 123-139. https://doi.org/10.1016/00401951(83)90013-6

Muro, A. D., Staudacher, T., Ferrazzini, V., Métrich, N., Besson, P., Garofalo, C., \& Villemant, B. (2015). Shallow Magma Storage at Piton de la Fournaise Volcano After 2007 Summit Caldera Collapse Tracked in Pele's Hairs. In R. Carey, V. Cayol, M. Poland, \& D. Weis (Eds.), Geophysical Monograph Series (pp. 189-212). John Wiley \& Sons, Inc. https://doi.org/10.1002/9781118872079.ch9

Peltier, A., Bachèlery, P., \& Staudacher, T. (2009). Magma transport and storage at Piton de La Fournaise (La Réunion) between 1972 and 2007: A review of geophysical and geochemical data. Journal of Volcanology and Geothermal Research, 184(1-2), 93-108. https://doi.org/10.1016/j.jvolgeores.2008.12.008

Peltier, A., Beauducel, F., Villeneuve, N., Ferrazzini, V., Di Muro, A., Aiuppa, A., Derrien, A., Jourde, K., \& Taisne, B. (2016). Deep fluid transfer evidenced by surface deformation during the 2014-2015 unrest at Piton de la Fournaise volcano. 
Journal of Volcanology and Geothermal Research, 321, 140-148. https://doi.org/10.1016/j.jvolgeores.2016.04.031

Peltier, A., Beauducel, F., Villeneuve, N., Ferrazzini, V., Muro, A. D., Aiuppa, A., Derrien, A., Jourde, K., \& Taisne, B. (2016). Deep fluid transfer evidenced by surface deformation during the 2014-2015 unrest at Piton de la Fournaise volcano. Journal of Volcanology and Geothermal Research, 321, 140-148. https://doi.org/10.1016/j.jvolgeores.2016.04.031

Peltier, A., Ferrazzini, V., Di Muro, A., Kowalski, P., Villeneuve, N., Richter, N., Chevrel, O., Froger, J. L., Hrysiewicz, A., Gouhier, M., Coppola, D., Retailleau, L., Beauducel, F., Gurioli, L., Boissier, P., Brunet, C., Catherine, P., Fontaine, F., Lauret, F., ... Ramsey, M. (2020). Volcano Crisis Management at Piton de la Fournaise (La Réunion) during the COVID-19 Lockdown. Seismological Research Letters. https://doi.org/10.1785/0220200212

Peltier, A., Staudacher, T., \& Bachèlery, P. (2010). New behaviour of the Piton de La Fournaise volcano feeding system (La Réunion Island) deduced from GPS data: Influence of the 2007 Dolomieu caldera collapse. Journal of Volcanology and Geothermal Research, 192(1-2), 48-56. https://doi.org/10.1016/j.jvolgeores.2010.02.007

Peltier, A., Villeneuve, N., Ferrazzini, V., Testud, S., Hassen Ali, T., Boissier, P., \& Catherine, P. (2018). Changes in the Long-Term Geophysical Eruptive Precursors at Piton de la Fournaise: Implications for the Response Management. Frontiers in Earth Science, 6, 104. https://doi.org/10.3389/feart.2018.00104

Pieri, D. C., Baloga, S. M., Nelson, R. M., \& Sagan, C. (1984). Sulfur flows of $\mathrm{Ra}$ Patera, lo. Icarus, 60(3), 685-700. https://doi.org/10.1016/00191035(84)90173-8

Rançon, J. P., Lerebour, P., \& Augé, T. (1989). The Grand Brule exploration drilling: New data on the deep framework of the Piton de la Fournaise volcano. Part 1: Lithostratigraphic units and volcanostructural implications. Journal of Volcanology and Geothermal Research, 36(1), 113-127. https://doi.org/10.1016/0377-0273(89)90008-5

Roult, G., Peltier, A., Taisne, B., Staudacher, T., Ferrazzini, V., \& Muro, A. [Di. (2012). A new comprehensive classification of the Piton de la Fournaise activity spanning the 1985-2010 period. Search and analysis of short-term precursors from a broad-band seismological station. Journal of Volcanology and Geothermal Research, 241-242, 78-104. https://doi.org/10.1016/j.jvolgeores.2012.06.012

Self, S., Gertisser, R., Thordarson, T., Rampino, M. R., \& Wolff, J. A. (2004). Magma volule, volatile emissions, and stratospheric aerosols from the 1815 eruption of Tambora. 31, 4.

Staudacher, T., \& Allègre, C. J. (1993). Ages of the second caldera of Piton de la Fournaise volcano (Réunion) determined by cosmic ray produced3He and21Ne. Earth and Planetary Science Letters, 119(3), 395-404. https://doi.org/10.1016/0012-821X(93)90147-2

Staudacher, T., Ferrazzini, V., Peltier, A., Kowalski, P., Boissier, P., Catherine, P., Lauret, F., \& Massin, F. (2009). The April 2007 eruption and the 
Dolomieu crater collapse, two major events at Piton de la Fournaise (La Réunion Island, Indian Ocean). Journal of Volcanology and Geothermal Research, 184(1), 126-137. https://doi.org/10.1016/j.jvolgeores.2008.11.005

Sundermeyer, C., Di Muro, A., Gordeychik, B., \& Wörner, G. (2019). Timescales of magmatic processes during the eruptive cycle 2014-2015 at Piton de la Fournaise, La Réunion, obtained from Mg-Fe diffusion modelling in olivine. Contributions to Mineralogy and Petrology, 175(1), 1. https://doi.org/10.1007/s00410-019-1642-y

Tepp, G., Hotovec-Ellis, A., Shiro, B., Johanson, I., Thelen, W., \& Haney, M. M. (2020). Seismic and geodetic progression of the 2018 summit caldera collapse of Kīlauea volcano. Earth and Planetary Science Letters, 540, 116250. https://doi.org/10.1016/j.epsl.2020.116250

Thornber, C. R. (2003). Kilauea East Rift Zone Magmatism: An Episode 54 Perspective. Journal of Petrology, 44(9), 1525-1559. https://doi.org/10.1093/petrology/egg048

Veefkind, J. P., Aben, I., McMullan, K., Förster, H., Vries, J. de, Otter, G., Claas, J., Eskes, H. J., Haan, J. F. de, Kleipool, Q., Weele, M. van, Hasekamp, O., Hoogeveen, R., Landgraf, J., Snel, R., Tol, P., Ingmann, P., Voors, R., Kruizinga, B., ... Levelt, P. F. (2012). TROPOMI on the ESA Sentinel-5 Precursor: A GMES mission for global observations of the atmospheric composition for climate, air quality and ozone layer applications. Remote Sensing of Environment, 120, 70 83. https://doi.org/10.1016/j.rse.2011.09.027

Wadge, G. (1981). The variation of magma discharge during basaltic eruptions. Journal of Volcanology and Geothermal Research, 11(2), 139-168. https://doi.org/10.1016/0377-0273(81)90020-2

Walker, G. P. L. (1988). Three Hawaiian calderas: An origin through loading by shallow intrusions? Journal of Geophysical Research: Solid Earth, 93(B12), 14773-14784. https://doi.org/10.1029/JB093iB12p14773

Wright, R. (2016). MODVOLC: 14 years of autonomous observations of effusive volcanism from space. Geological Society, London, Special Publications, 426(1), 23-53. https://doi.org/10.1144/SP426.12

Wright, R., Blake, S., Harris, A. J. L., \& Rothery, D. A. (2001). A simple explanation for the space-based calculation of lava eruption rates. Earth and Planetary Science Letters, 192(2), 223-233. https://doi.org/10.1016/S0012821X(01)00443-5

Wright, R., Flynn, L., Garbeil, H., Harris, A., \& Pilger, E. (2002). Automated volcanic eruption detection using MODIS. Remote Sensing of Environment, 82(1), 135-155. https://doi.org/10.1016/S0034-4257(02)00030-5

Yang, K., Dickerson, R. R., Carn, S. A., Ge, C., \& Wang, J. (2013). First observations of SO2 from the satellite Suomi NPP OMPS: Widespread air pollution events over China. Geophysical Research Letters, 40(18), 4957-4962. https://doi.org/10.1002/grl.50952 
Appendix 1: Sulfur dioxide emissions at Piton de la Fournaise during the eruptions of interest recorded by the Ozone Monitoring Instrument (OMI), the Ozone Mapping and Profiler Suite (OMPS) and the Tropospheric Monitoring Instrument (TROPOMI).

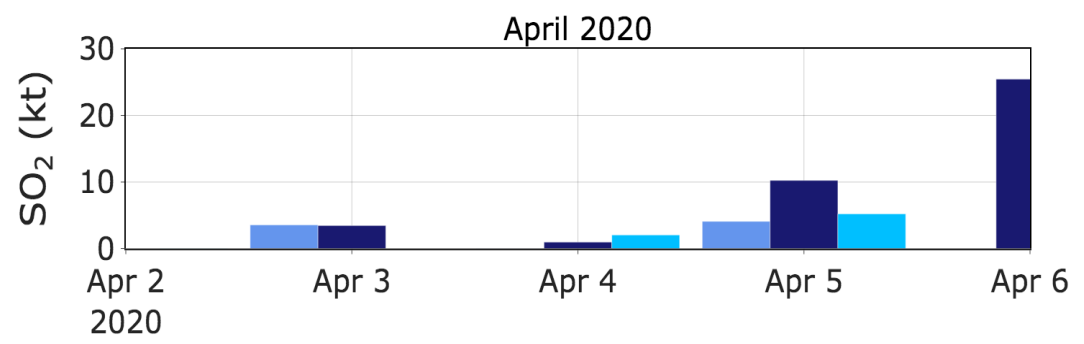

February 2019

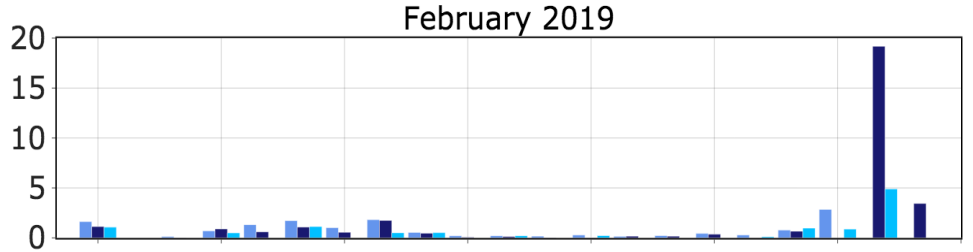

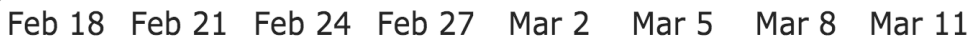
2019
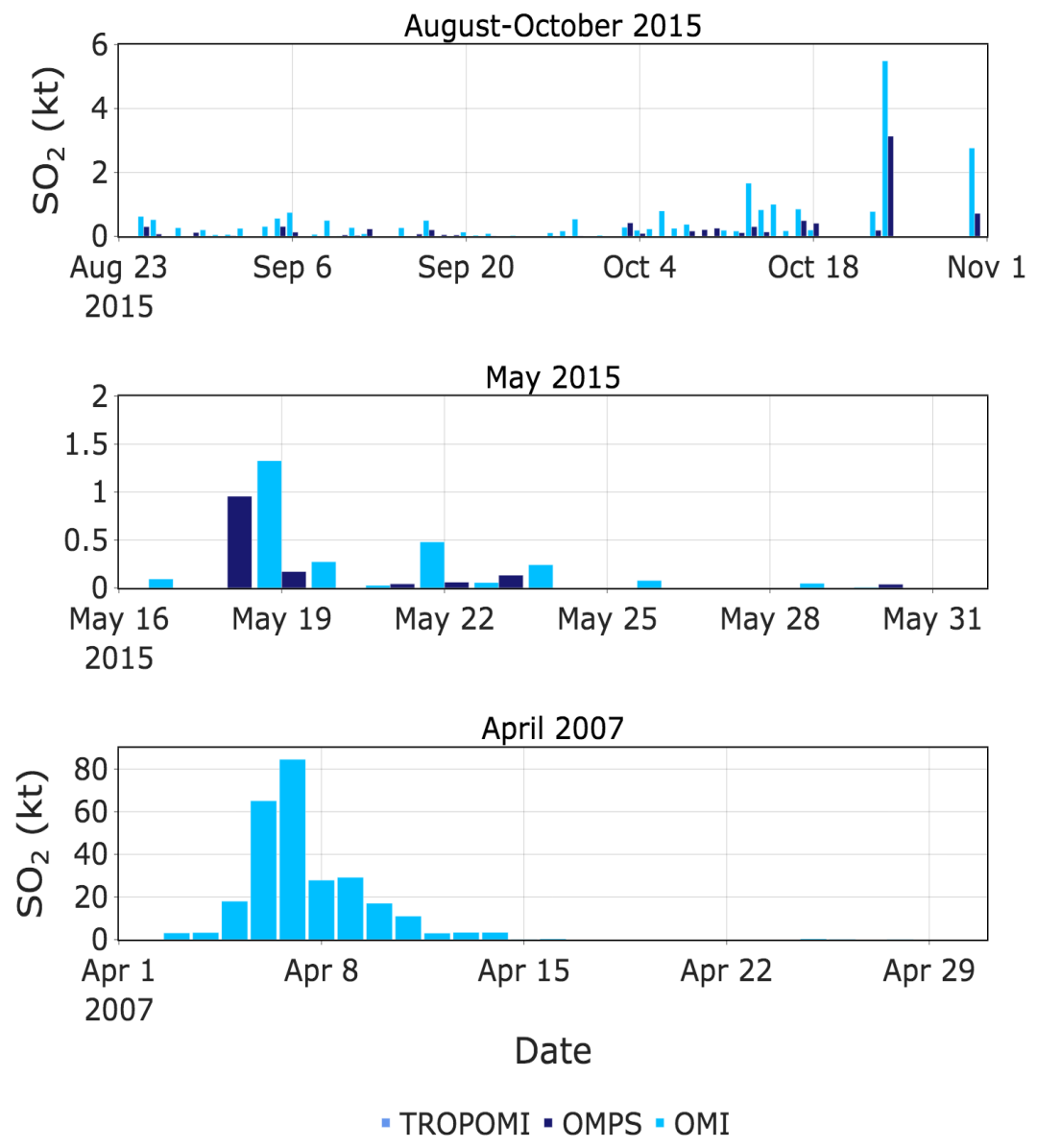
Appendix 2: Piton de la Fournaise. (a.) The effusion rates and (b.) the cumulative volumes of erupted lava for the following eruptions: April 2020, February 2019, August-October 2015, May 2015 and April 2007. The estimations correspond to the MIROVA and MODVOLC automatic systems but also to the Manual method.

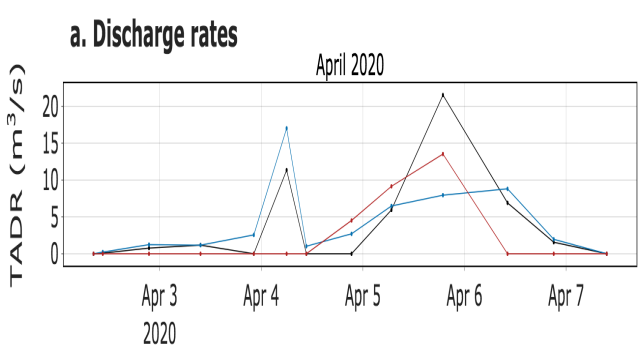

February 2019

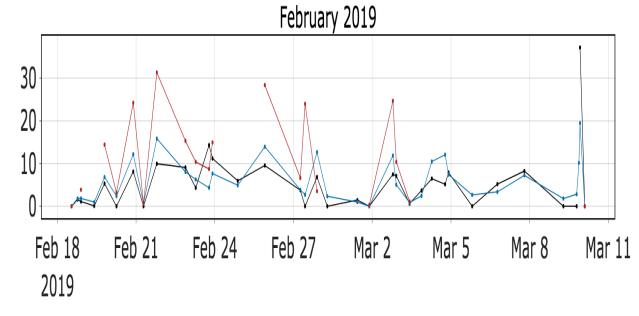

August-October 2015

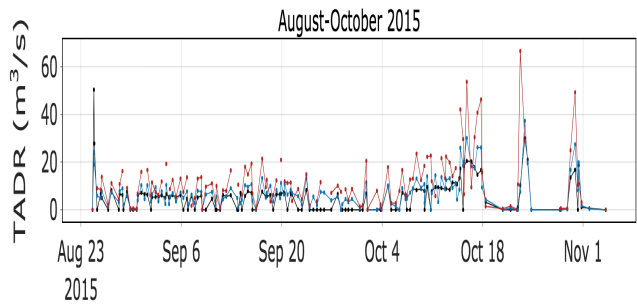

May 2015

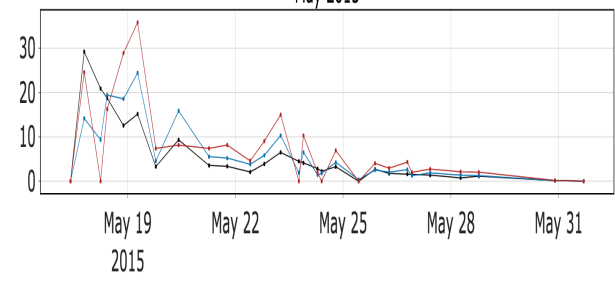

April 2007

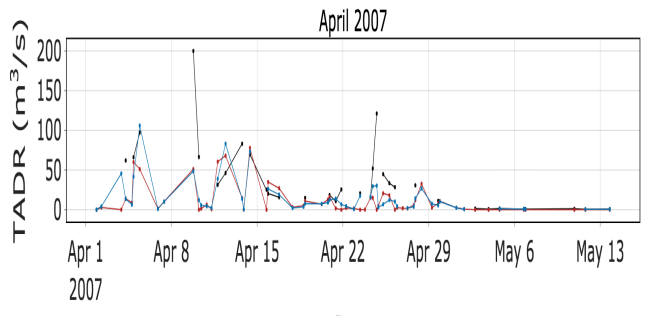

Date

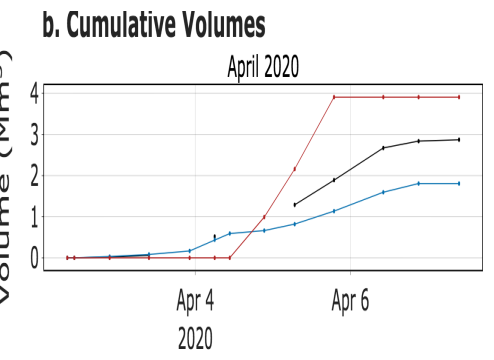

February 2019
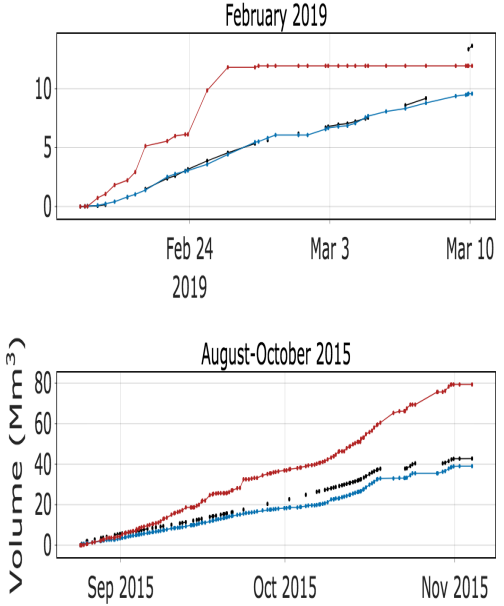

May 2015
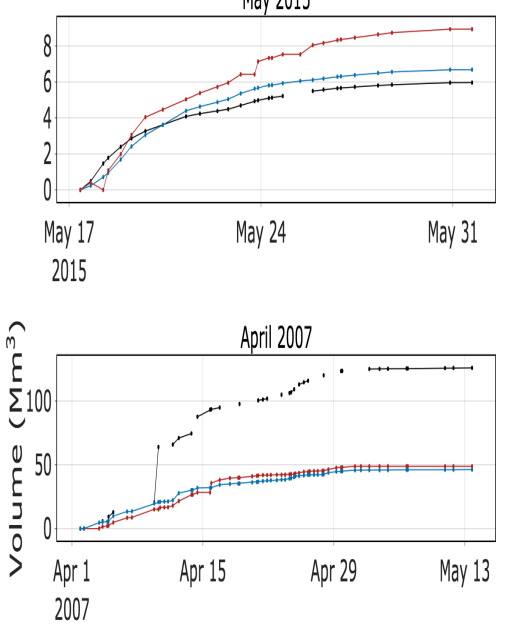

Date

-MIROVA-MODVOLC-Manual 
Appendix 3: Figure from (Coppola et al., 2010). (a) Bow tie effect on the MODIS image. We can see two pairs of pixels detected as hot spots resulting in (b) two scan lines from the same surface thus producing a double counting at scan angle of about $45^{\circ}$.

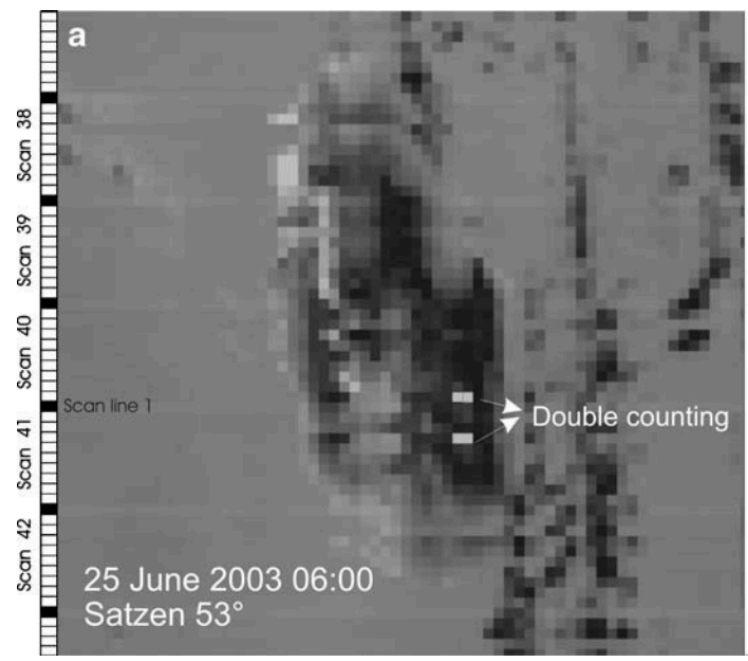

b

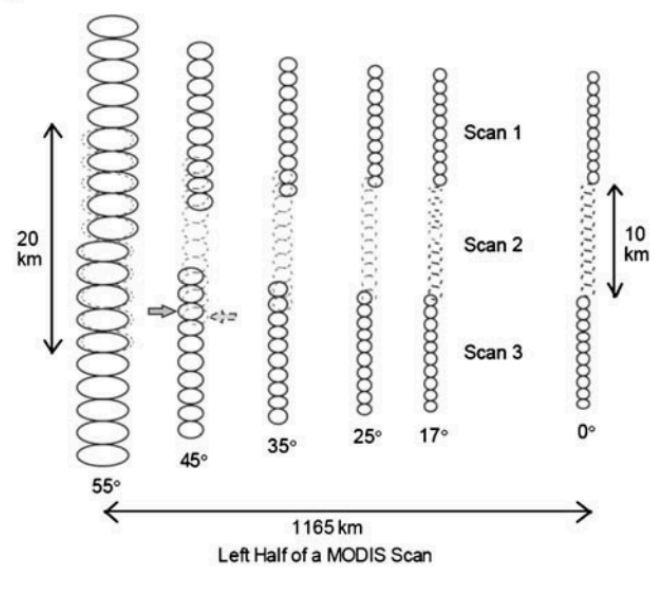

